رفاد للدراسات والأبحاث

www.refaad.com
المجلة الدولية للدراسات التربوية والنفسية

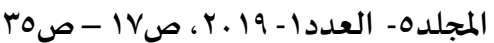

e-ISSN 2520-4149, p-ISSN 2520-4130

\title{
العلاقة بين الذكاء الانفعالي والوعي الأمني لدى طلاب جامعة تبوك
}

\author{
حباب عبد الحي محممد عثثمان \\ أستاذ علم النفس المساعد- بكلية التربية والآداب- جامعة تبوك- السعودية \\ h-othman@ut.edu.sa
}

الملخص:

تهدف الدراسة إلى التعرف على العلاقة بين الذكاء الانفعالي والوعي بالمخاطر الأمنية لدى طلاب جامعة تبوك، استخدم الباحث المنهج الوصفي

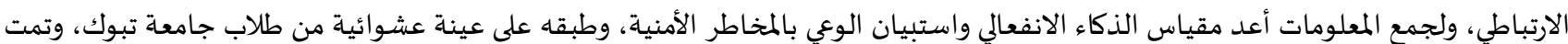
معالجة البيانات عبر برنامج الحزم الإحصائية SPSS ، وأسفر البحث عن النتائج التالية : توجد علاقة (طردية) إيجابية ذات دلالة إحصيائية بين

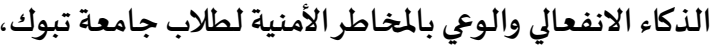
• توجد علاقة إيجابية ذات دلالة إحصائية بين الذكاء الإنفعالي والوعي بمخاطر الإرهاب • توجد علاقة إيجابية ذات دلالة إحصائية بين الذكاء الإنفعالي والوعي بمخاطر المخدرات، توجد علاقة إيجابية ذات دلالة إحصائية بين الذكاء الانفعالي والوعي بمخاطر حوادث المرور • توجد علاقة إيجابية ذات دلالة إحصائية بين الذكاء الانفعالي والوعي بمخاطر الفساد الأخلاقي • كما توجد علاقة بين أبعاد الذكاء الإنفعالي (اليسر الانفعالي- المشاركة الوجدانية- الدافعية والوعى بالذات- تنظيم وإدارة الانفعالات- الحالة المزاجياة) وأبعاد الوعي الأمني (الإرهاب- المخدرات-المرور - الفساد الاخلاقي).

الكلمات المفتاحية: الذكاء الانفعالي، الوعي الأمني، الإرهاب، المخدرات، المرور، الفساد الأخلاقي (c) (1)

الوعي الأمني عملية عقلية مهمة لحماية الأفكار من التصدي للمخاطر الأمنية التي تهدد المجتمع ،و لتطوير هذا الوعي لابد من إصلاح المنظومة التربوية والتعليمية في اتجاه القطع مع الأنساق الفكرية والقيمية التي تساهم في نشر الأفكار الإنحرافية الخطرة .وتنص سياسة التعليم في المملكة العربية السعودية على ضرورة تربية الطلاب على "احترام الحقوق العامة التي كفلها الإسلام وشرع حمايتها حفاظاً على الأمن، وتحقيقاً لاستقرار المجتمع ، وعلى تربية المواطن ليكون لبناة صالحة في بناء أمته، ويشعر بمسؤوليته لخدمة بلاده والدفاع عنها، وعلى "تنمية إحساس الطلاب بمشكلات المجاتهمع...

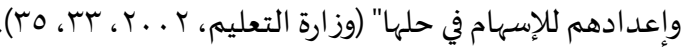
تهدف التوعية الأمنية إلى غرس المعرفة الأمنية في أذهان أفراد المجتمع من خلال تمليكهم المعلومات اللازمة لتحقيق الأمن والسلم في المجتمع، و

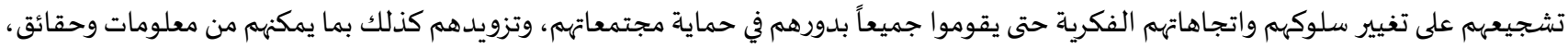

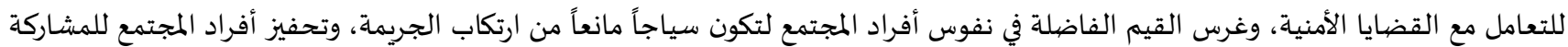
الإيجابية واستشعار المسؤولية نحو المجتمع ، و تمكين المواطنين من معرفة مهددات الأمن القومي وكيفية مواجهة هذه التحديات تحقيقا لأمن الوطن.



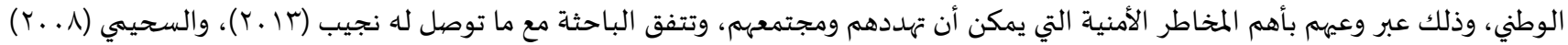

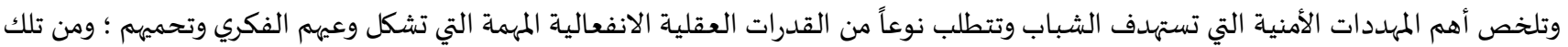
المخاطر الأمنية الآتية : أولاً: انتشار الإرهاب والعنف والتحريض السيهاتياسي والتطرف الديني، فيجب أن يقود الذكاء الأفراد نحو الوعي بتعظيم هيبة الدولة، وتعميق الشعور الوطني، والولاء للقادة، والانتماء للوطن، وتعزيز الوحدة الوطنية، وغرس روح المشاركة، وتحمل المسؤولية، والمحافظة على استقرار و استمرار النظام السياسي؛ كما أن الوعي الأمني يعني إيجاد آلية للرقابة الجماهيرية والدستورية واءونية والقانونية التي تحفظ الاستقرار للنظام السياسي وتعمل على ديمومتها. 


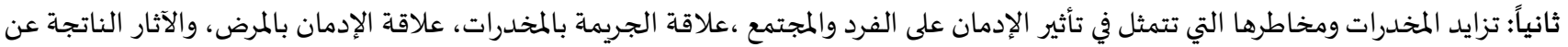

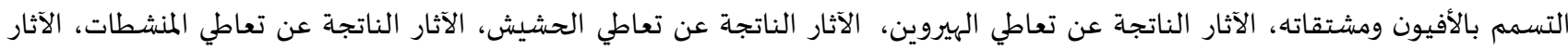

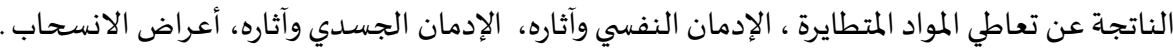

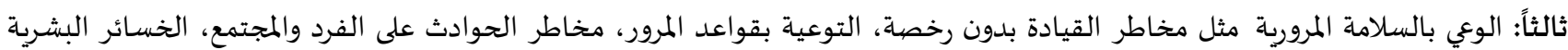

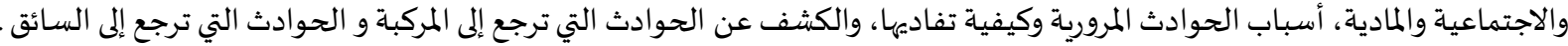

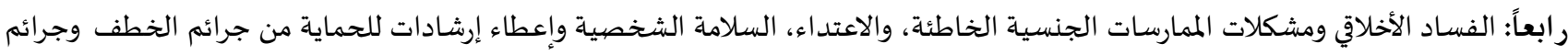
القتل والاعتداء الجنسي. ويحاول هذا البحث أن يتناول تلك المخاطر الأمنية بالكثف عن العلاقة بين متغير مهم في بناء شخصية الفرد وهو الذكاء الانفعالي ومتغير الوعي الأمني.

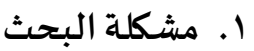

الذكاء الانفعالي كقدرة عقلية يمثل نوعاً من أهم الذكاءات ويسهم في تشكيل وعي الفرد المعرفي والانفعالي، وذلك من خلال الاستجابات

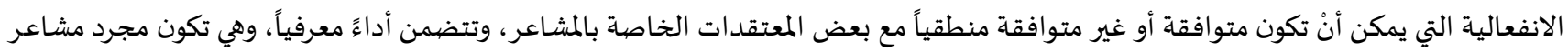

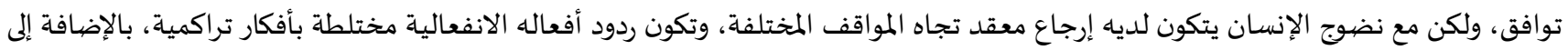

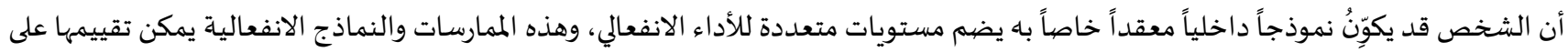

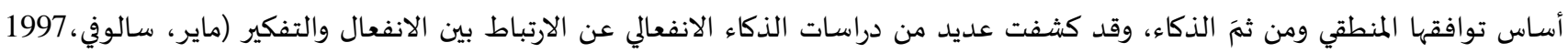

(Mayer, J. D., \& Salovey

ومن هنا تنطلق مشكلة البحث في تناول متغير حديث مهم هو الذكاء الانفعالي وتحاول إيجاد علاقته بمتغير آخر هو الوعي باعتباره مكونا

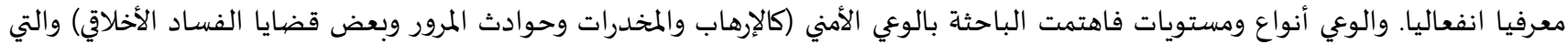

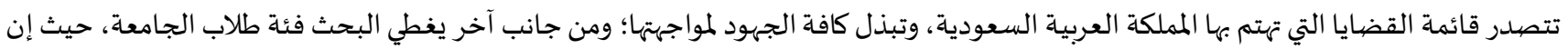

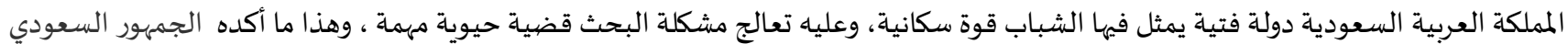

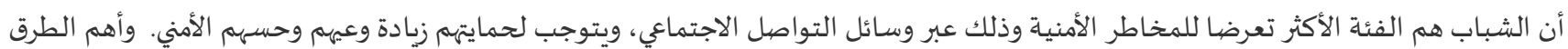

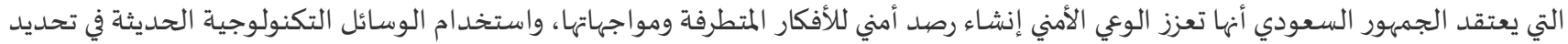

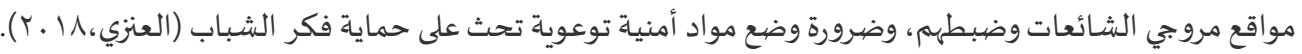

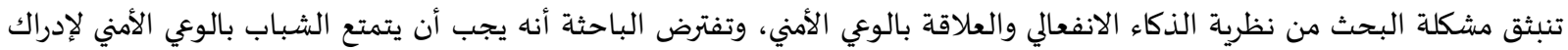

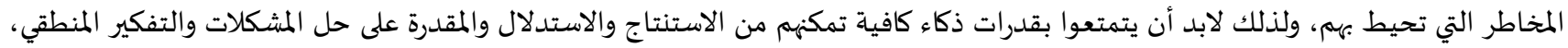

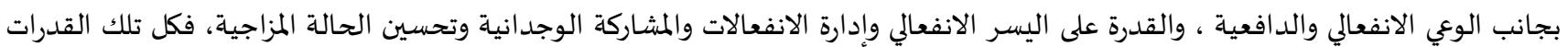

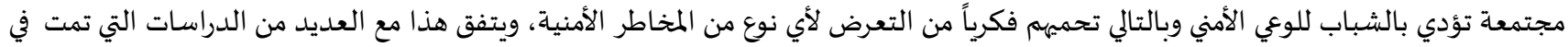

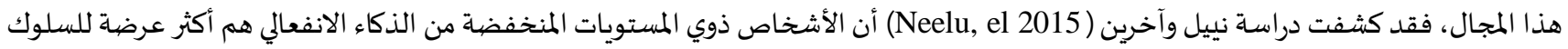

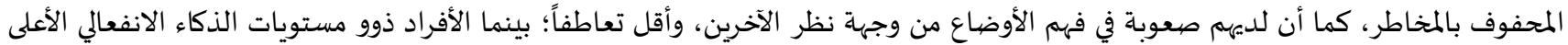

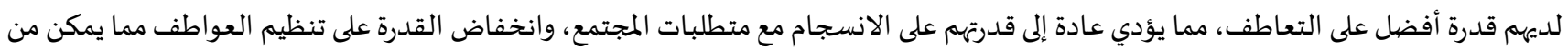
الحفاظ على نمط مخالف للسلوك في المجرمين.

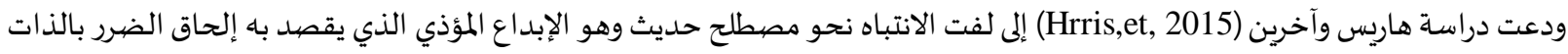

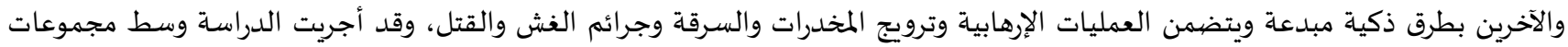

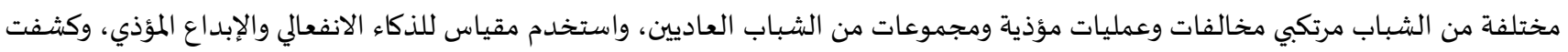

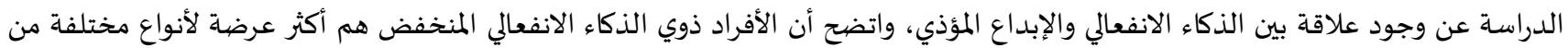
المشاكل، كما تزيد وسطهم حالات الإبداع المؤذي.

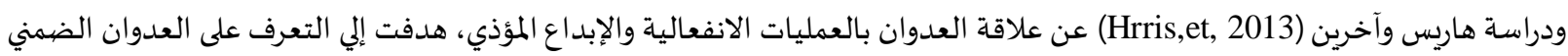



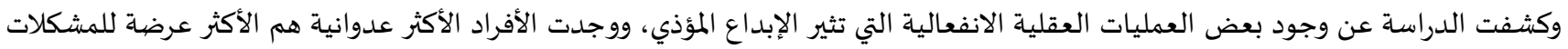
الدينية والعمليات المؤذية، وهم أكثر إبداعاءئ الإيذاء. 
ومن جانب آخر بينت دراسة ديفيد وآخرين (David,et,al 2008) أن الإبداع المؤذي يمثل نموذجا وظيفيا إبداعيا للإرهاب والجريمة، وأن

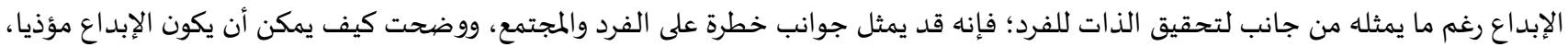



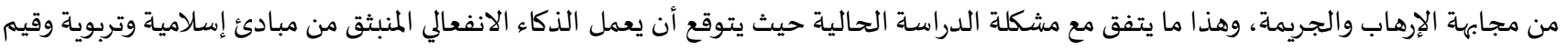

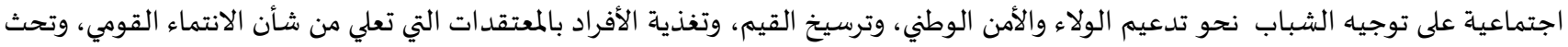

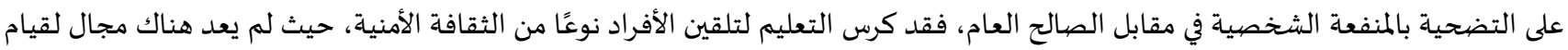

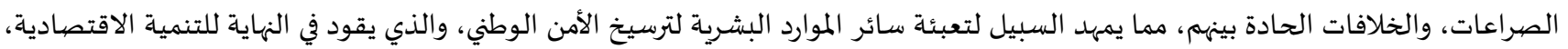

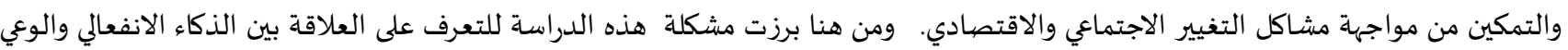

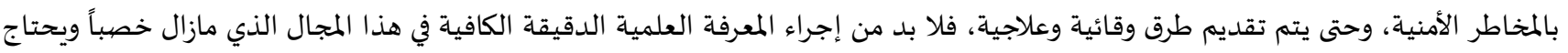

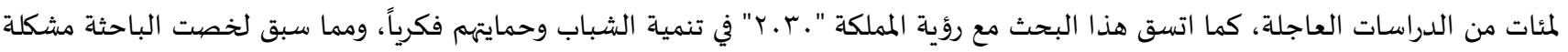

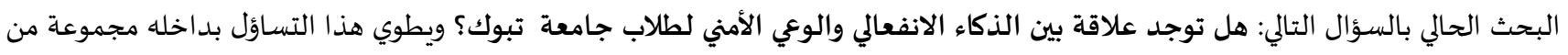

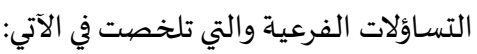

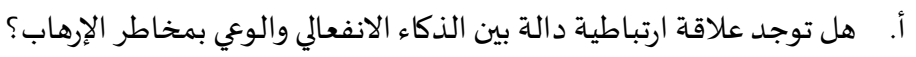

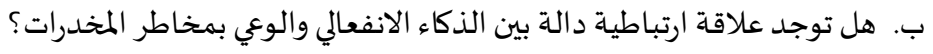

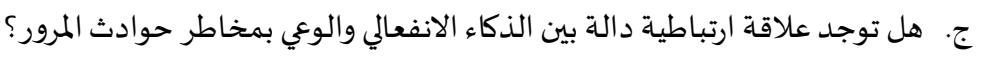

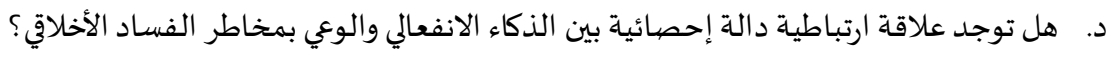

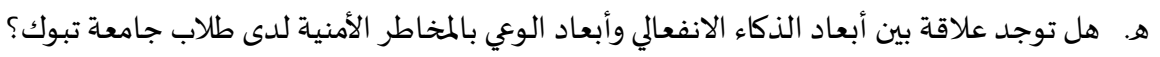

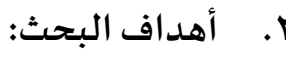 \\ يهدف البحث إلى تحقيق الأهداف الآتية:-}

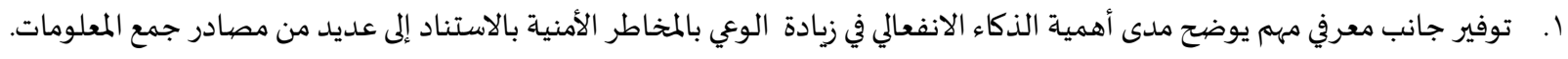

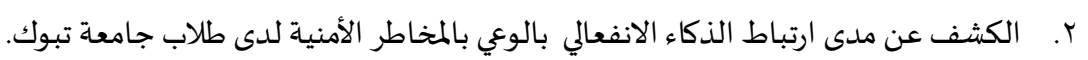

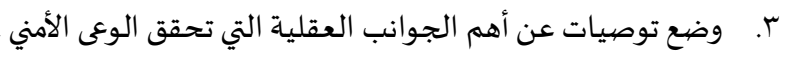

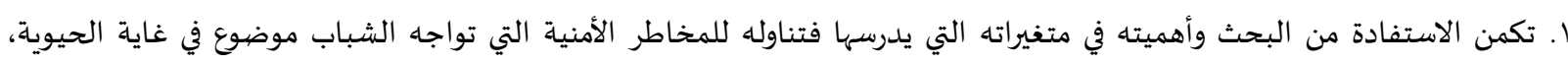

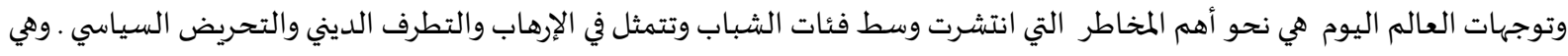

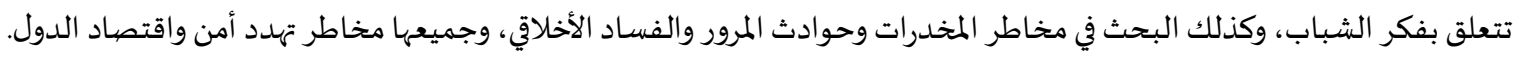

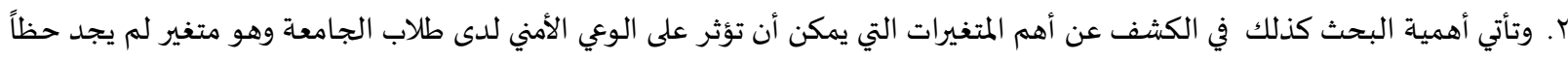

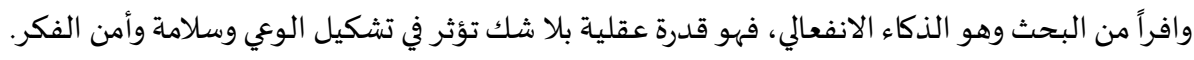

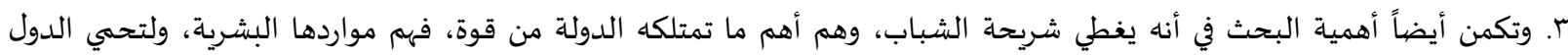

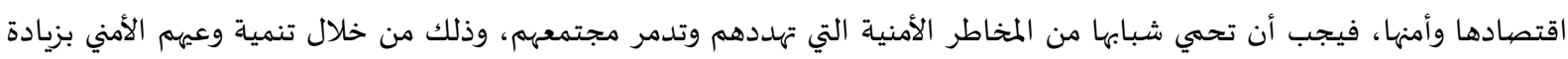
قدراتهم الانفعالية. عـ. كما تتضح أهمية هذا البحث في أنه يمثل لبنة أساسية لوضع البرامج والإرشادات والأسس الوقائية والعلاجية لمواجهة المخاطر الأمنية التي

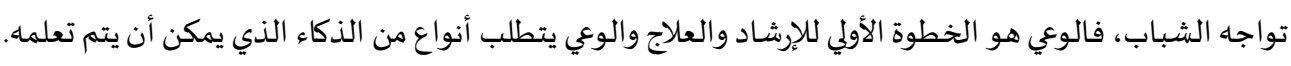

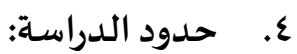

الحدود الموضوعية: الذكاء الانفعالي- الوعى الأمني بقضايا الإرهاب والمخدرات وحوادة المادث المرور والفساد الأخلاقاقي.

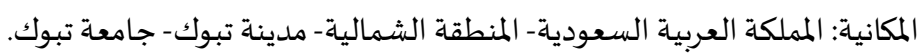
البشرية: طلاب الجامعة -كلية التربية والآداب- ذكور وأنات.

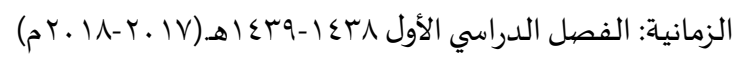




\section{0. مصطلحات البحث:}

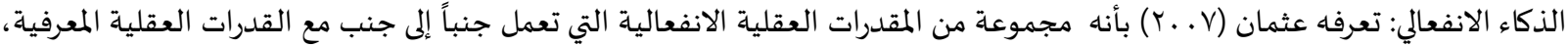

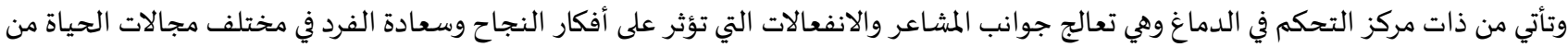
خلال العديد من المهارات الوجدانية الناتجة عن التعلم والتربية والخبرة الجيدة. ويتمثل الذكاء الانفعالي في القدرات العقلية الانفعالية التي تشكل

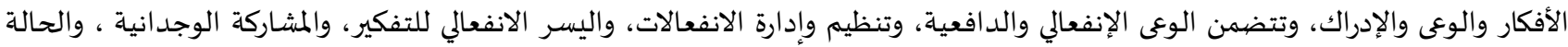

المزاجية

إجرائيا: الذكاء الانفعالي هو القدرات الانفعالية التي تقيسها أداة الدراسـة الحالية وتتمثل في (الوعي الانفعالي والدافعياة- والتنظيم الانفعالي- واليسر الانفعالي- والحالة المزاجية-و المشاركة الوجدانيانة الموانية). الوعي الأمني: تعرف الباحثة الوعي بأنه عملية عقلية ناتجة عن ذكاء الفرد، ويندرج الأمن في هرم ماسلو ضمن الحاجات المكتسبة؛ فهو حاجة روحية

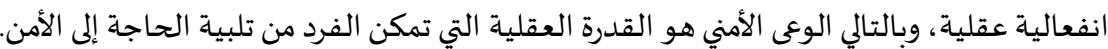

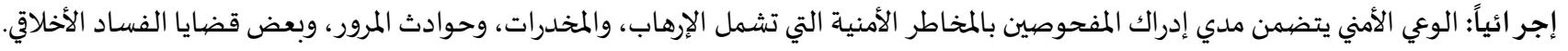

\section{7. الإطار النظري:}

استخدم الذكاء الانفعالي كمادة أسـاسية في التعليم، وأصبحت دراسة العاطفة مادة تطبق في مجال التربية، وظهرت فاعلية هذا البرنامج بأن

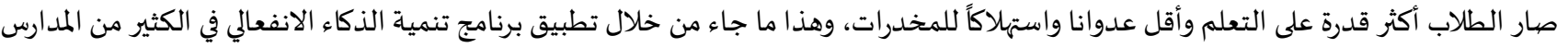
والجامعات الأمريكية (جولمان،Golman, 1996) واتضيح أن مؤسسات التعليم التي تهتم على نحو نسقي بتنمية المهارات الاجتماعية والانفعالية لطالاها تعمل على رفع مستوى إنجازهم الأكاديمي، وتناقص مشكلاتهم السلوكية، وتنمية اتجاهاتهم وأنماطهم السلوكية وتكويناتهم المعرفية، وبالتالي تتحسن جودة العلاقات التي تحيط بالفرد، ويصبح الأفراد أكثر إنتاجية، ومسؤولية، ويكونوا أعضاء مسـاهمين في المجتمع مما يحقق أمن المجتمع. وتدل

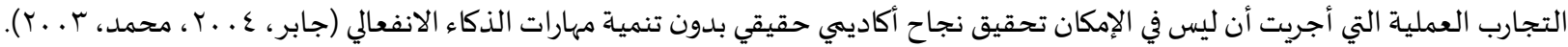

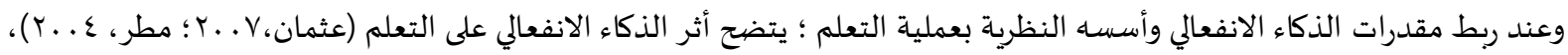
وتكشف فسيولوجية الدماغ علاقة المخ الانفعالي (emotional brain) بالمناطق التنفيذية للمخ brain executive area وفصوص المخ التي وراء

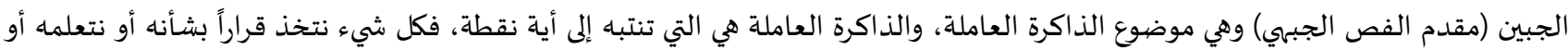
نحسناه يكون أولاً في الذاكرة العاملة، والمراكز الانفعالية التي تضبط وتسيطر على الحالة المزاجية كالقلق أو الغضب لها لهورابه روابط قوية بمناطق مقدمة

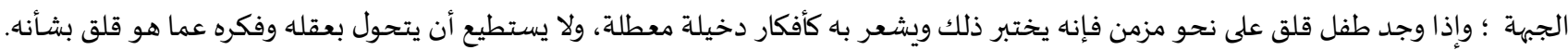

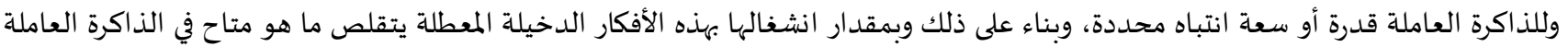

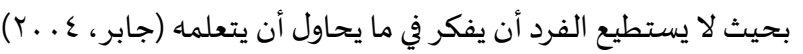

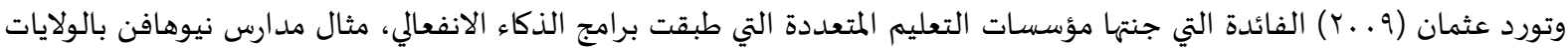
المتحدة الأمريكية التي طبقت البرنامج من الصف الأول الابتدائي حتى نهاية المرحلة الثانوية، والبرنامج يتناول جميع مهارات الوعي الإنفعالي والتفاهم

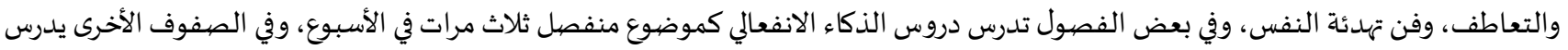
كجزء من مقررات مثل الصحة وحتى الرياضيات أو مهارات الاستذكار، وتقوم مناهج جميع المدارس الأمريكية حالياً على ألفة ومعرفة بالأفكار، ويتحينون الفرص لتدريسها، وفي هذه المدارس يستخدمون أساليب تجعل الاستجابات الانفعالية الصحية مدمجة فئ في ثقافة المدرسة أو أو بيئتها، وعلي سبيل المثال يوجد على حائط كل حجرة ملصق عليه علامة قف المرورية! وهذا الملصق يبين للطلاب كلما تعرضوا للانفعال الشديد والتعاسة والانزعاج

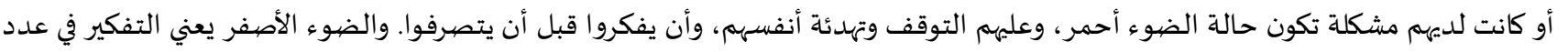
من الأشياء المختلفة تستطيع عملها والعواقب أو النتائج التي تترتب على ذلك، وأنَ على الطالب أن يختار أفضلها ويجربه، ويعتبر هذا درس رائع في ضبط ئه

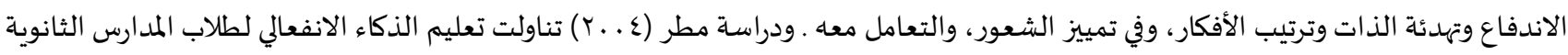
للتقليل من درجات العنف ووجدت استجابات جيدة. وتعرض عثمان (V . .. ما بينتاه جاردنر أن آلية العمل بين اللوزة "التي تحدث الاستجابة الأكثر تروي" وبين القشرة القبلجبهية كنموذج

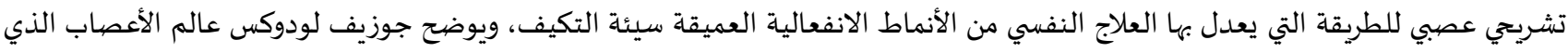

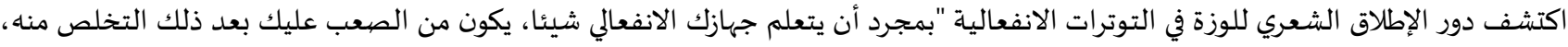
وما يفعله العلاج النفسي هو أن يعلمك كيف تتحكم في هذا الشيء و أن يعلم قشرتك الجديدة كيف تكبح مركز الانفعال، حيث يتم قمع النزول إلى الى

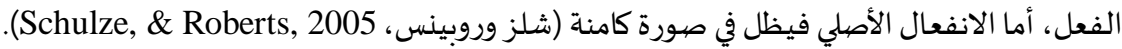


ومن خلال فهمنا لبنية المخ المسؤولة عن إعادة التعلم الانفعالي ترى جاردنر (V . . r) أن ما يتبقى من العلاج النفسي الناجح مجرد استجابة

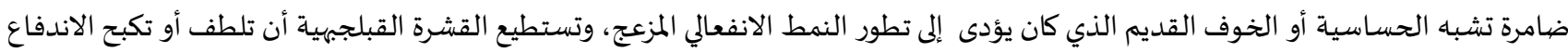

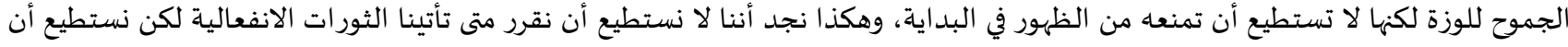

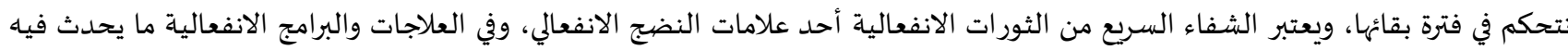

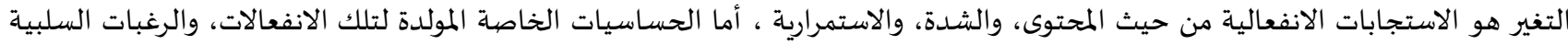

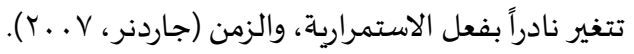

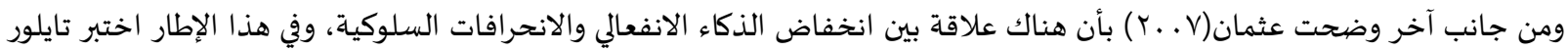
تناول العاطفة غير الصادقة وساهم في توضيح كيف أنها تطور المشاكل الشخصية والعلاقات وتطبع قلقا عاطفيا وواقعا مؤلما، وجاء ببرهان لأهمية الربط بين الكلمات غير الصادقة والاضطرابات النفسية مثال "سوء استخدام القيمة" و واضطية "اضطرابات الكلام" (كيروشي وفورقاس وماير،Cirrochi,forgas, Mayer,2001). كما أن مهارات الذكاء الانفعالي لازمة للصحة،، ووضح ذلك عبد الهادي (ץ. ..ب) إذ إن مقدرات ومهارات


تعمل على تخفيف ضربات القلب (عبد الهادي، r. r. r).

جدول(1): أقسام نظام الشخصية كما وضحها مايروسالوفي وكارسو (Mayer , Salovey., \& Caruso, 2000)

\begin{tabular}{|c|c|}
\hline الاساسي & في الشخصية \\
\hline الدوافع" الحاجة للإنجاز - الحاجة للانتماء- الحاجة للقوة" مستويات الدوافع & والتعاون يمثل المستوى الأدنى من الدوافع العاطفية في نظام الشخصية، والدوافع \\
\hline \multirow{2}{*}{ |الحستقرار العاطفي". العواطف" الحب- السعادة-الغضب- الحزن" والأساليب العاطفية" } & \multirow[t]{2}{*}{ | العاطفية هي المسؤولة عن الحوافز الأساسية للأفراد. } \\
\hline & \\
\hline \multirow{2}{*}{ | والتشاءؤ ومعالجة التفاء الذكاءل". - الذكاء الذاء الانفعالي". الأساليب الإدراكية " التفاؤل } & \multirow{2}{*}{ الآخرين، وتفعيل المعرفة مخلوفة معلومات الشخصية، للأحاسيس والأفكار عن الذات وعن } \\
\hline & \\
\hline \multirow{2}{*}{ | لعبرة" الانطواء الذاتي- الدفء-البرودة" المهارات المعبرة " مقدرة لعب الدور- } & \multirow{2}{*}{ قالمهيم الشخصية الداخلية للعالم الخارجي. ويخص النشاطات والأدوار الاجتماعية } \\
\hline & \\
\hline \multirow[t]{2}{*}{ | الوعي" المعرفة وعدم المعرفة، الضمير الذاتي" والإمكانات العالية والمنخفضية } & ل الواعي: يحتوي مكان الوعي على الوعي والضمير معا " التحكم في \\
\hline & \\
\hline
\end{tabular}

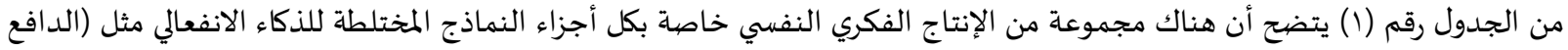

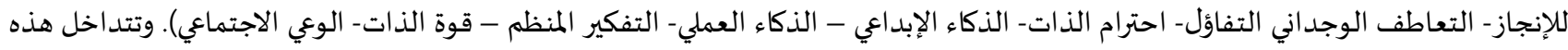

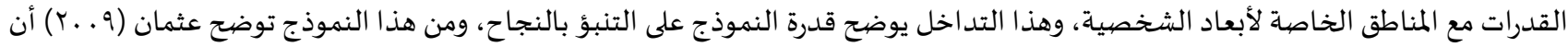

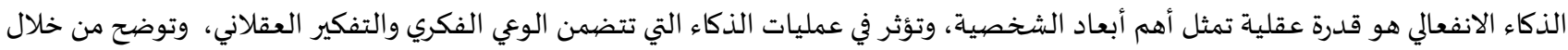

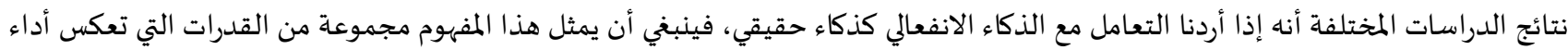

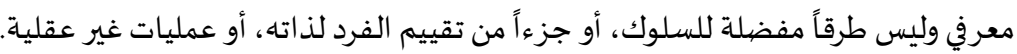



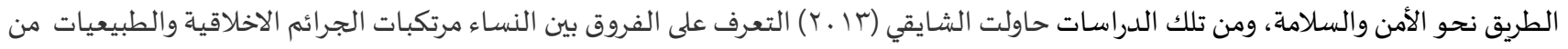


المرض- الهيستريا- الانحراف السيكوباتي- البارنويا- السكاثينيا- الفصام- الهوس الخفيف)، كما سجلت مرتكبات الجرائم الاخلاقية درجات عالية في

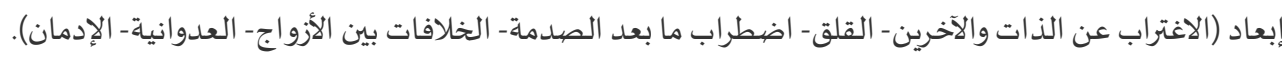
إن أكثر أنواع الاستثمارات الرأسمالية قيمة هو ما يستثمر من البشر، وهنالك من الأدلة الإمبريقية ما يؤكد ذلك، فاليابان لم تحقق هضيتها

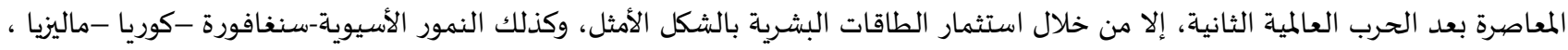

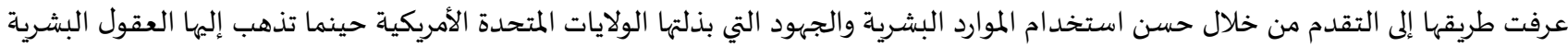

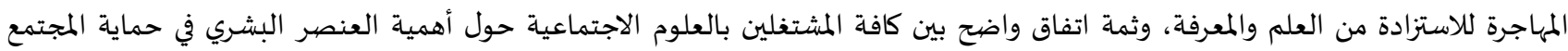



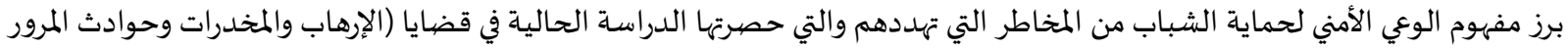

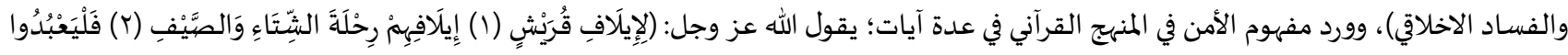

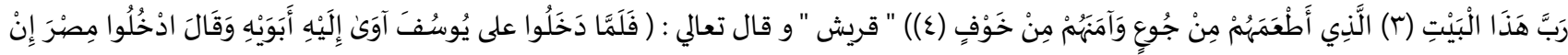




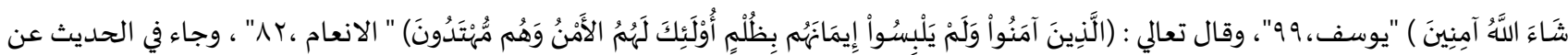

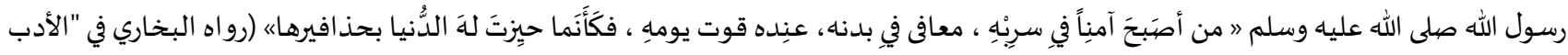



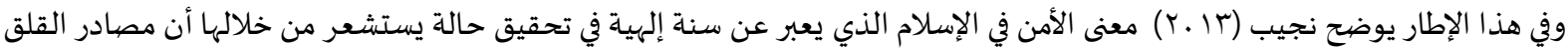

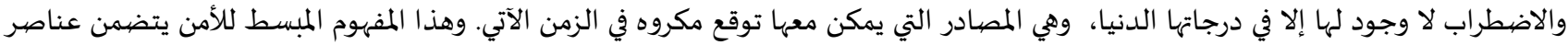

أولاً: إن الأمن يعبر عن سنة إلهية من حيث لا يخرج عن سنن الله في خلقه وفي تدبيره للكون والحياة.

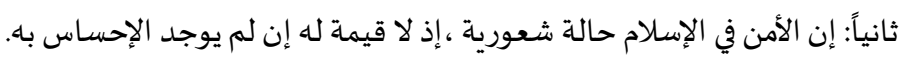
ثالثاً: إن طبيعة الأمن كإحساس أو شعور تستلزم الكائنات الحية.

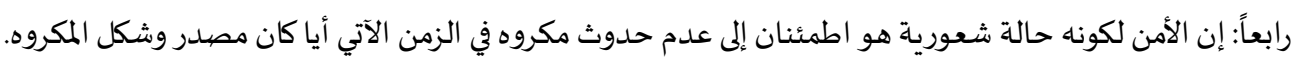

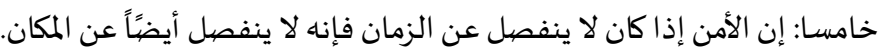

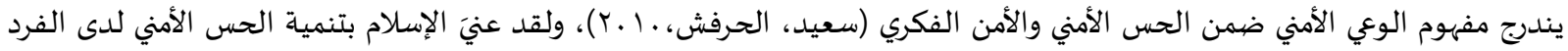

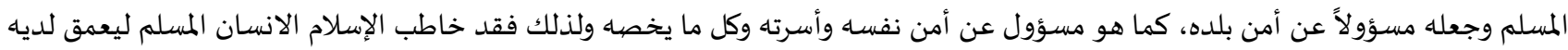
الشعور بالمسؤولية سواءً الفردية أو الجماعية كما في قوله تعالى: (ولا تقفُ ما ليس لك باه علم، إن السمع والبصر والفؤاد كل أولئك كان عنها مسئولا) "الأسراء، بr" .

سادسا : الحسّ الأمني هو استشعار الأخطار ومصادرها والتصدي لها وهي عملية ترتبط بالإدراك والعمليات العقلية للفرد.

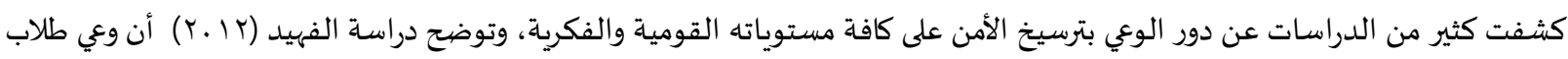

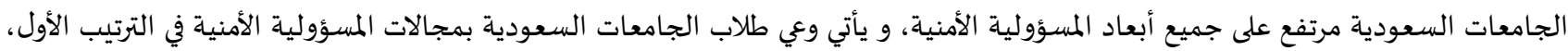

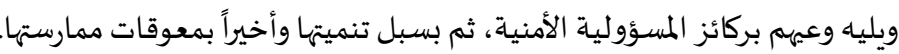

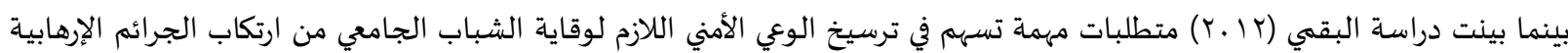

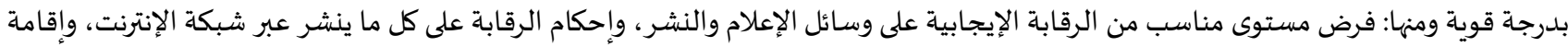

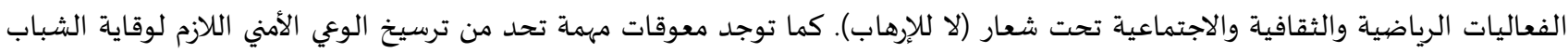

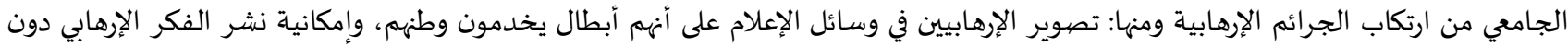

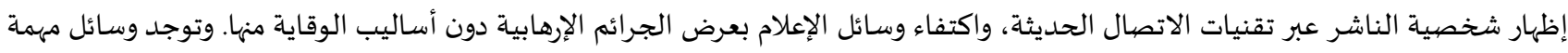

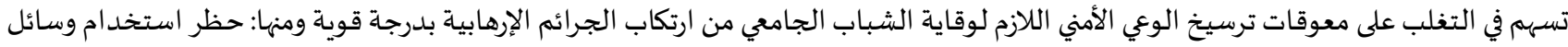

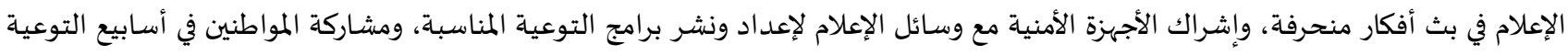

الأمنية التي تنظمها أجهزة مكافحة الإرهاب. وتحاول هذه الدراسة أن تسهم في الكشف عن استراتيجيات عقلية تحمي الأمن الوطني من خلال نوع مهم من الذكاء الإنساني يؤثر على الوعي

الأمني.

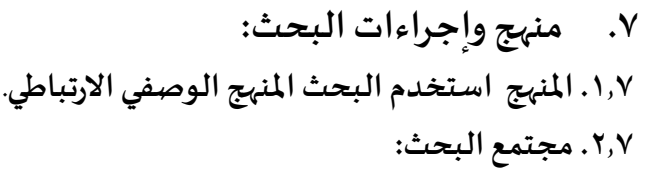

تمثل المجتمع من حيث الحدود البشرية في طلاب وطالبات جامعة تبوك، ومن حيث الحدود الجغرافية تحدد في مدينة تبوك فقط. ومن حيث

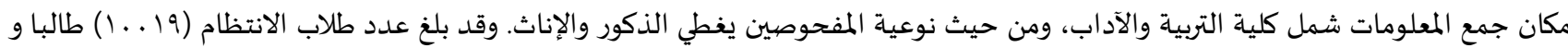

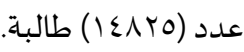
r,V

استخدمت الطريقة الطبقية العشوائية البسيطة لاختيار عينة البحث، وبالطريقة العشوائية البسيطة عبر القصاصات الورقية تم اختيار

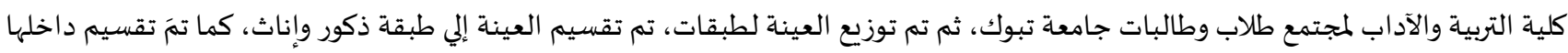

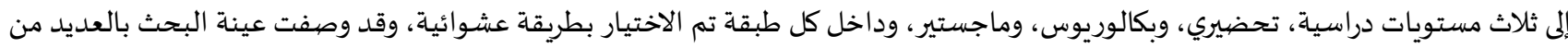

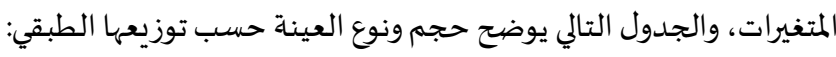


جدول (r) ) يوضح توصيف عينة البحث تبعاً لتوزيعها

\begin{tabular}{|c|c|c|c|}
\hline المجموع & التكرار & التدرج & متغيرات التوصيف \\
\hline & 1.0 & ذكور & \multirow[t]{3}{*}{ النوع } \\
\hline & or. & إناث & \\
\hline \multirow[t]{4}{*}{$\% 1 .}$. & $7 r o$ & المجموع & \\
\hline & r1o & تحضيري & \multirow[t]{4}{*}{ المستوي الدراسي } \\
\hline & rr. & بكالوريوس & \\
\hline & 11. & دبلوم وماجستير & \\
\hline$\% 1 .$. & Tro & المجموع & \\
\hline
\end{tabular}

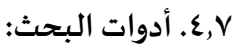

استمارة البيانات الأولية: صهمت للحصول على المعلومات الأولية عن المفحوصين، وبها إرشادات تطبيق المقياس، وتضمنت المتغيرات المتعلقة بالمفحوصين مثل المتغيرات الديموغرافية والاجتماعية والأكاديمياة، وعرضت الاستمارة مرفقة مع المقياس على المحكمين، وأخذ بجميع توصيات

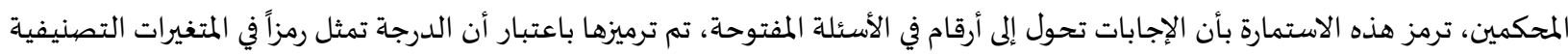

$$
\text { وتمثل رتباً في بعض المتغيرات. }
$$

مقياس الذكاء الانفعالي: إن الأداة المستخدمة في البحث الحالي هي مقياس الذكاء الانفعالي (عثمان، V. . . )، وطريقة القياس التي استخدمها، هي

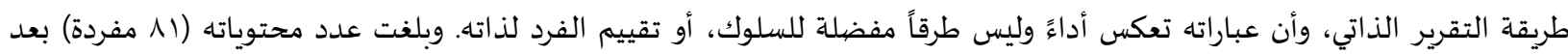
تعديلات صدق المحتوي.

ثبات وصداق المقياس: تم التحقق من حساب معامل ثبات المقياس عن طريق الاتساق الداخلي و بلغ معدل الثبات ألفا كرونباخ (7ع人, •). وهي

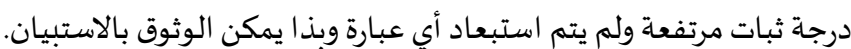

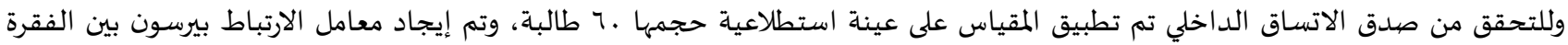

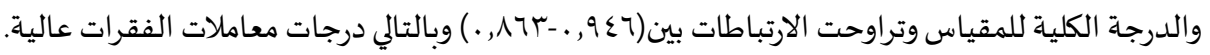

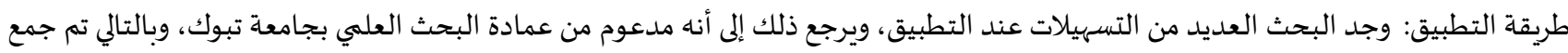

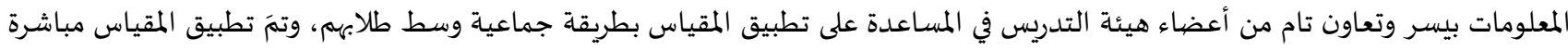
وعدم ترك الأوراق مع المفحوصين. 0,V ترميز وإدخال البيانات واستخدام المعالجات الإحصائية باستخدام برنامج 24 IBM SPSS Statistics لاستخلاص النتائج. ولإجابة عن السؤال الأول استخدمت التكرارات والنسبة المئوية، واختبار (ت) لعينتين مستقلتين غير مرتبطتين، و معامل ارتباط بيرسون.

1. 1. 1. . عرض النتائج ومناقشتها:

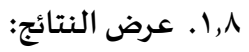
الفرض الأول: للتحقق من الفرض الذي نصيه "توجد علاقة ذات دلالة إحصيائية بين الذكاء الانفعالي والوعي بالمخـاطر الأمنية لطلاب جامعة تبوك" استخدم معامل ارتباط (بيرسون) والجداول التالية توضح النوضئ النتائج:

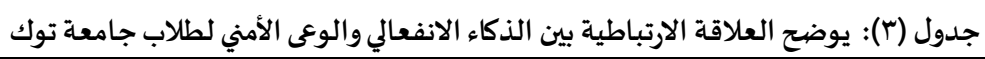

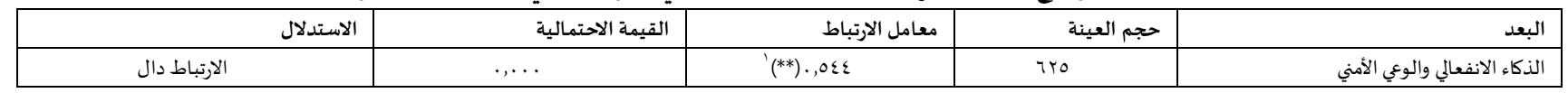


جدول(ع): يوضح العلاقة الارتباطية بين الذكاء الانفعالي والوعى بمخاطر الإرهاب لطلاب جامعة تبوك العاب العابة

\begin{tabular}{|c|c|c|c|c|}
\hline الاستدلال & القيمة الاحتمالية & معامل الارتباط & حجم العينة & البعد \\
\hline الارتباط دال & $\ldots$ & $(* *) ., \varepsilon \leqslant r$ & $7 \% 0$ & الذكاء الانفحالي والوعي بالإرهاب \\
\hline
\end{tabular}

توجد علاقة ذات دلالة إحصائية بين الذكاء الانفعالي والوعي بمخاطر المخدرات لطلاب جامعة تبوك.

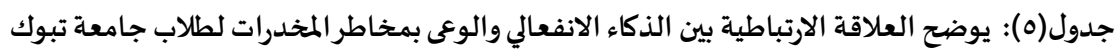

\begin{tabular}{|c|c|c|c|c|}
\hline الاستدلال & القيمة الاحتمالية & معامل الارتباط & حجم العينة & البعد \\
\hline الارتباط دال & $\ldots$ &., 011 & Tro & الذكاء الانفعالي والوعي بالمخدرات \\
\hline
\end{tabular}

• توجد علاقة ذات دلالة إحصيائية بين الذكاء الانفعالي والوعي بمخاطر المرور لطلاب جامعة تبوك .

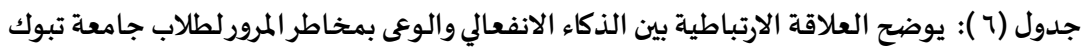

\begin{tabular}{|c|c|c|c|c|}
\hline الاستدلال & القيمة الاحتمالية & معامل الارتباط & حجم العينة & البعد \\
\hline الارتباط دال & $\ldots$ & $(* *) ., \varepsilon Y\}$ & Tro & الذكاء الانفعالي والوعي بالمرور \\
\hline
\end{tabular}

• توجد علاقة ذات دلالة إحصيائية بين الذكاء الانفعالي والوعي بالمخاطر الأخلاقية لطلاب جامعة تبوك .



\begin{tabular}{|c|c|c|c|c|}
\hline الاستدلال & القيمة الاحتمالية & معامل الارتباط & حجم العينة & البعد \\
\hline الارتباط دال &.,$\ldots$ & $(* *), 0$ TV & Tro & الذكاء الانفعالي والوعي بالأخلاق \\
\hline
\end{tabular}

الفرض الثاني: للتحقق من صححة الفرض الذي نصهـ توجـد علاقـة ارتباطية بين أبعاد الذكاء الانفعالي و إبعاد الوعي الأمني، استخدم معامل ارتباط بيرسون وتم التوصل للنتائج التالية: جدول (^ ): يوضح أبعاد الذكاء الوجداني وعلاقتها بأبعاد الوعي الأمني

\begin{tabular}{|c|c|c|c|c|c|c|}
\hline \multicolumn{5}{|c|}{ الوعي الأمني وأبعاده } & \multirow[t]{2}{*}{ البيان } & \multirow[t]{2}{*}{ 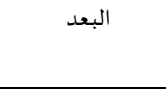 } \\
\hline الاخلاق & المرور & المخدرات & الارهاب & الدرجة الكلية & & \\
\hline$(* *) ., \sum T V$ & $(* *), r$, rar & $(* *) ., \sum 7 \Gamma$ & $(* *), \varepsilon \mathrm{TV}$ & $(* *) \cdot, 00 \leqslant$ & م. م. الارتباط & \multirow{3}{*}{ الدرجة الكلية } \\
\hline.,$\ldots$ & ${ }^{\prime}, \ldots$ & 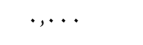 & 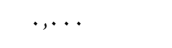 & 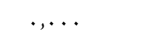 & القيمة الاحتمالية & \\
\hline الارتباط دال & الارتباط دال & الارتباط دال & الارتباط دال & الارتباط دال & الاستدلال & \\
\hline$(* *) ., r 99$ & $(* *) \cdot, \varepsilon r\}$ & $(* *)$, , rqv & $(* *), r 997$ & $(* *) \cdot, 01 \mathrm{~V}$ & م. الارتباط & \multirow[t]{3}{*}{ اليسر الانفعالي } \\
\hline.,$\ldots$ & $\ldots$ & $\ldots$ &.,$\ldots$ & $\ldots$ & القيمة الاحتمالية & \\
\hline الارتباط دال & الارتباط دال & الارتباط دال & الارتباط دال & الارتباط دال & الاستدلال & \\
\hline$(* *) .$, rq4 & $(* *), \varepsilon r q$ & $(* *) \cdot, r .7$ & $(* *), r \wedge \varepsilon$ & $(* *), r, r \varepsilon$ & م. الارتباط & \multirow[t]{3}{*}{ المشاركة الوجدانية } \\
\hline$\ldots$ & $\ldots$ & $\ldots$ &.,$\ldots$ & $\ldots$ & القيمة الاحتمالية & \\
\hline الارتباط دال & الارتباط دال & الارتباط دال & الارتباط دال & الارتباط دال & الاستدلال & \\
\hline$(* *) ., T Y \varepsilon$ & $(* *), r \varepsilon$ & $(* *), r 79$ & $(* *),, r T$. & $(* *)$, \&।V & م. الارتباط & \multirow{3}{*}{ بالذات الدعية والوعي } \\
\hline$\ldots$ & $\ldots$ & $\cdot, \ldots$ & ${ }^{\prime, \ldots}$ & $\ldots$ & القيمة الاحتمالية & \\
\hline الارتباط دال & الارتباط دال & الارتباط دال & الارتباط دال & الارتباط دال & الاستدلال & \\
\hline$(* *) ., \varepsilon r T$ & $(* *)$, rq & $(* *),, M \neg T$ & $(* *) ., 490$ & $(* *)$, , 01 & م. الارتباط & \multirow{3}{*}{ تنظيم وإدارة } \\
\hline$\ldots$ & 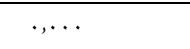 & $\ldots$ & $\cdot, \ldots$ &.,$\ldots$ & القيمة الاحتمالية & \\
\hline الارتباط دال & الارتباط دال & الارتباط دال & الارتباط دال & الارتباط دال & الاستدلال & \\
\hline$(* *), r \wedge \Lambda$ & $(* *) \cdot$, rา9 & $(* *), r+r q$ & $(* *)$, , \&70 & $(* *), r \wedge r$ & م. الارتباط & \multirow[t]{3}{*}{ الحالة المزاجية } \\
\hline$\cdot, \ldots$ & 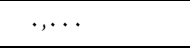 & $\cdot, \cdots$ & $\cdots$ & 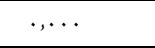 & القيمة الاحتمالية & \\
\hline الارتباط دال & الارتباط دال & الارتباط دال & الارتباط دال & الارتباط دال & الاستدلال & \\
\hline
\end{tabular}

عند استخدام معامل ارتباط بيرسون، وحجم العينة من . ـ ه-أقل من . . 1 تكون قيم ومستويات الدلالة كالاتي: القيمة (088. ، 05.)، (115.، 01.) (147.، 001.). 
بالنظر إلى الجدول أعلاه والذي يتضمن العلاقة بين أبعاد الذكاء الانفعالي بالدرجة الكلية للوعي الأمني وأبعاده وفق ارتباط (بيرسون) نلاحظ أن

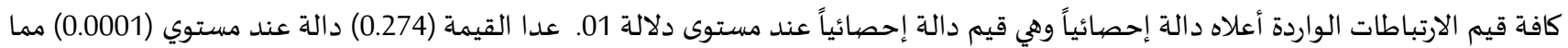

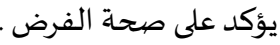

إذن النتيجة : توجد علاقة طردية دالة إحصائياً بين أبعاد الذكاء الانفعالي و أبعاد الوعي الأمني.

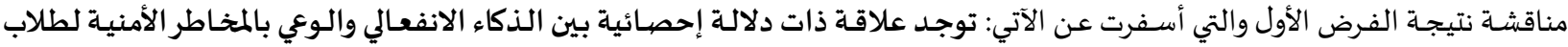
جامعة تبوك.

تفسر هذه النتيجة من خلال أدبيات البحث، والتي ترتكز على أن الحسّ الأمني هو استشعار الأخطار ومصادرها والتصدي لها وهي عملية ترتبط بالإدراك والعمليات العقلية للفرد. وقد كشفت كثير من الدراسات عن دور الوعي بترسيخ الأمن على كافة مستوياته القومي والفكري والاقتصادي، وتحاول الباحثة تفسير

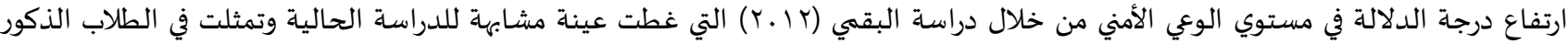

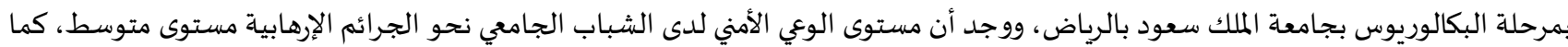

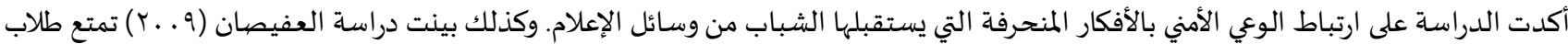



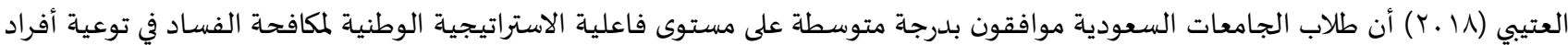


النزاهة ومكافحة الفساد وتطبيقها على أرض الواقح.

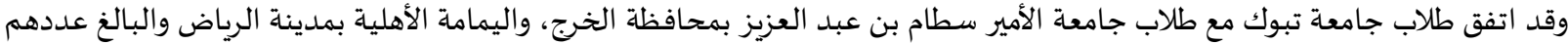
(VAN)





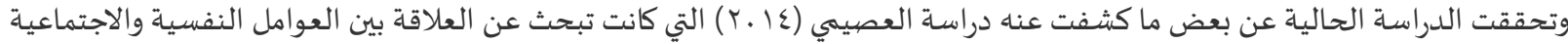

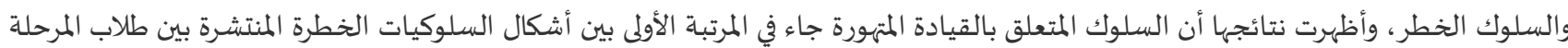

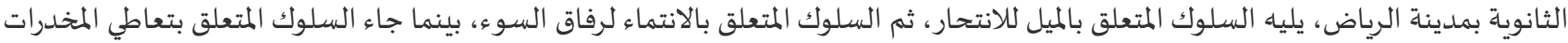

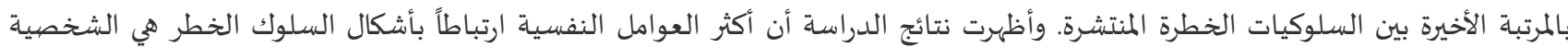

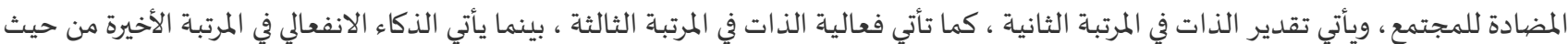
العوامل النفسية الأكثر ارتباطاً بأشكال السلوك الخطر المرتبة التران.



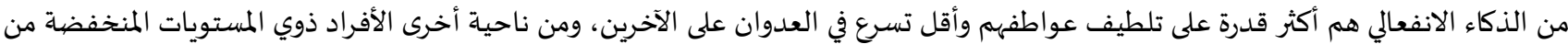

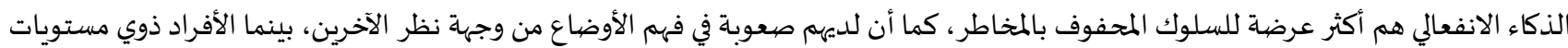

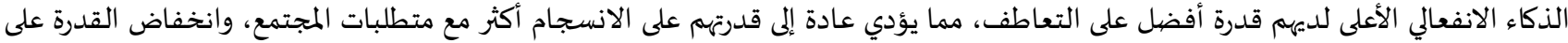
تنظيم العواطف يمكن أن تحافظ على الابتعاد عن السلوك الاجرامئ الإني. من جانب آخر استشهدت الباحثة ببعض الدراسات الحديثة التي تناولت العلاقة بين الذكاء الانفعالي والإبداع المؤذي وهو مصطلح حدائ الإيث،

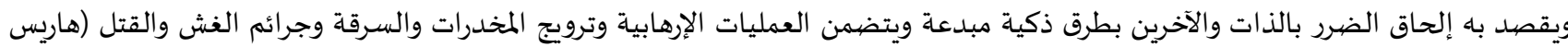

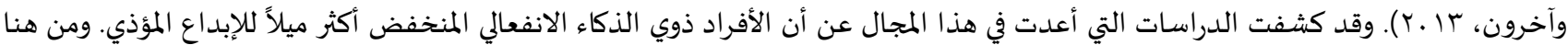



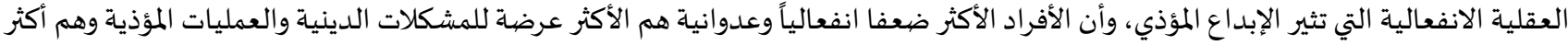

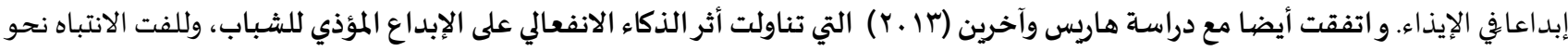

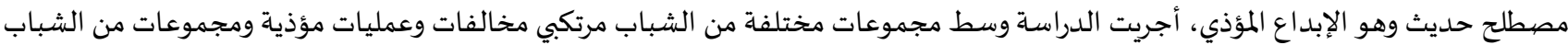


ذوي الذكاء الانفعالي المنخفض هم أكثر عرضة لأنواع مختلفة من المشاكل، كما تزيد وسطهم حالات الإنداع الإداع المؤذي. 
لا تتفق أو تختلف الدراسة الحالية مع دراسـة ميلاني وآخرين (Melanie,et,al,2014) عن الإبداع الكاذب والعلاقة بين الذكاء والنزاهة،

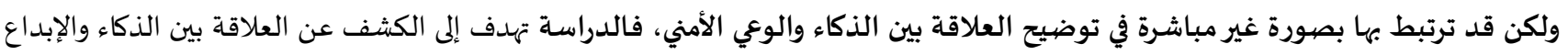
الكاذب والنزاهة ، وتفترض الدراسة الذكاء يؤدي للنزاهة بينما الإبداع المؤذي يسبب الضرر سهواً أو عمداً، وأن القيم والمعتقدات هي التي توجه الذكاء

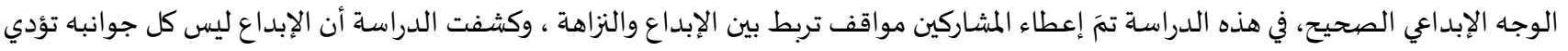

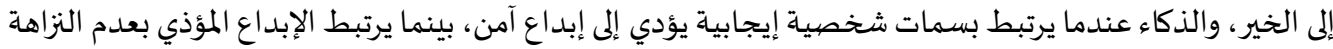

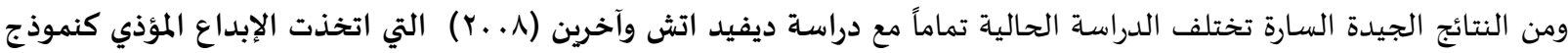

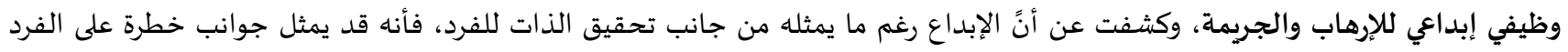

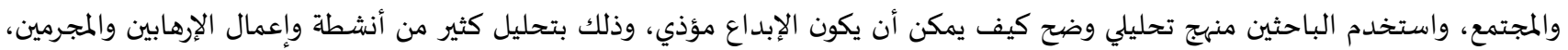

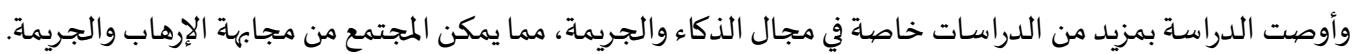



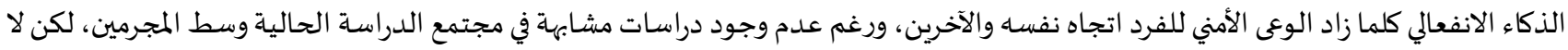

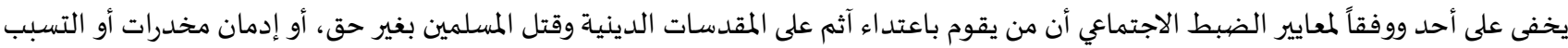

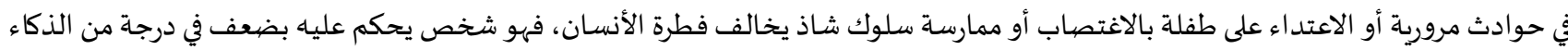
الانفعالي.

مناقشة الفرض الثاني: الفرض الثاني: توجد علاقة طردية دالة إحصيائياً بين أبعاد الذكاء الانفعالي و أبعاد الوعي الأمني.

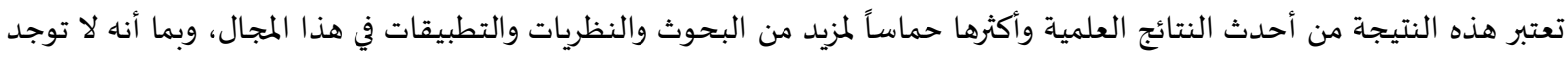
دراسات مباشرة ذات علاقة بالأبعاد وفي الفرض الأول تم عرض ومناقشة الدرجة الكلية للمتغيرات، لذلك تحاول الباحثة تفسير الفرض من خلال

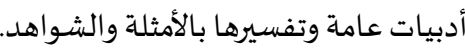

ومن أهم الدراسات التي تدعم نتائج هذا الفرض بأبعاده المختلفة الدراسة التي طبقت للكشف عدف عن الذكاء الانفعالي والجريمة، والتي تم

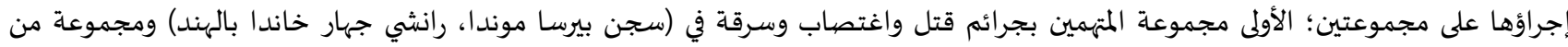

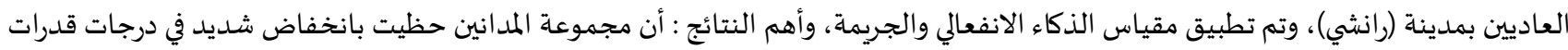

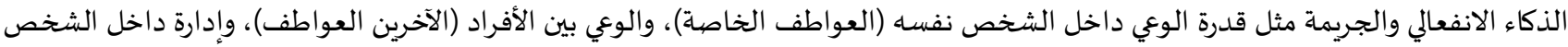

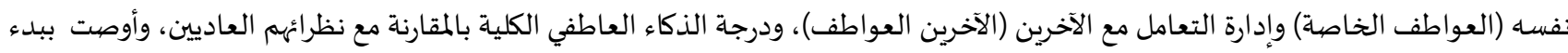
تشغيل برنامج تعزيز EI في السجن لمساعدة السجناء على فهم أفضل لمشاعرهم وعواطفهمه

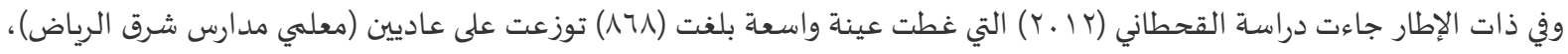
سجناء جرائم (أخلاقية- مخدرات- عنف)، وقد وجدت فروق ذات دات دلالة إحصائية واضحة بين السجناء والعاديين لصالح السجناء، واتسمت فئة

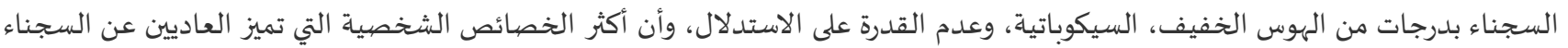



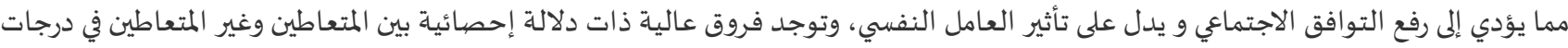

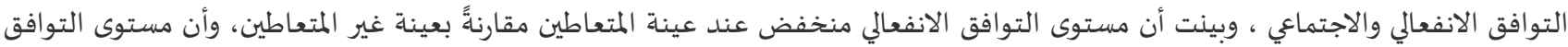

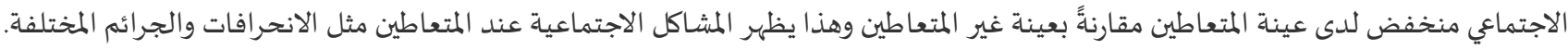
ووضحت دراسة حجاب (1) ـ ( وجود فروق ذات دلالة إحصائية في عوامل الشخصية المتمثلة في( كفاية الذات، التخيل، الثبات الانفعالي، التآلف) بين المدمنين وغير المدمنين لصالح المدمنين. وبينت دراسـة بوسنة (0 ـ ـ أن الإنسان هو المسؤول الأول عن المركبة والطريق وعن نفساه فهو يساهم وبنسبة كبيرة في وقوع هذه المآسي المرورية ، ولهذا ركزنا من خلال هذه الدراسة على العامل البشري وتأثيره على ارتفاع حوادث المرور محاولين معرفة الأسباب التي تجعل الإنسان يقوم

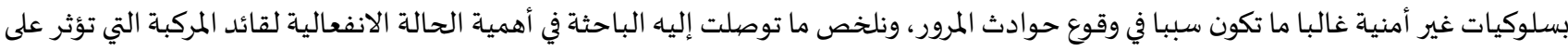
التفكير والوعي والإدراك والتفهم والانتباه والتركيز.

أولاً: توجد علاقة ارتباطية دالة بين اليسر الانفعالي والوعي بمخاطر الإرهاب والمخدرات واتلفرات والمروروالأخلاق.

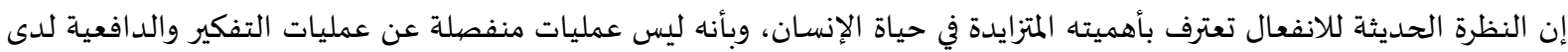
الإنسان، بل هي عمليات متداخلة مكملة لبعضها البعض، وأن الجانب المعرفي لدى الإنسان يسهم إيجاباً في العمليات الانفعالية من خلال تفسير 


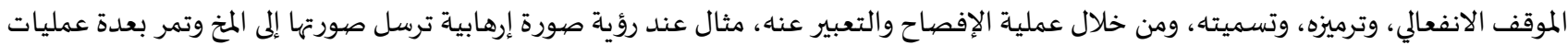

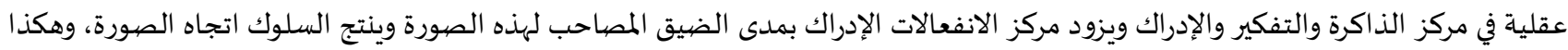
في أي عملية عقلية. فإذن تسهم عملية تسهيل الانفعالات للتفكير في زيادة الوعي الأمني للفرد، فكلما كان للفرد قدرة عقلية عالية في المعالجات الانفعالية كان



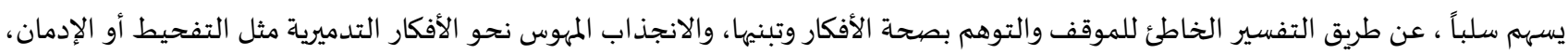

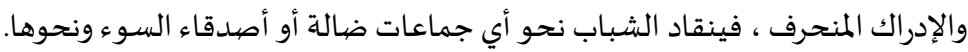

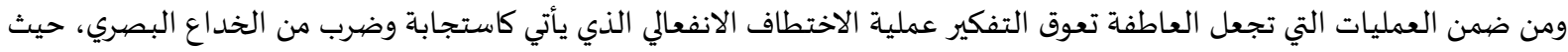

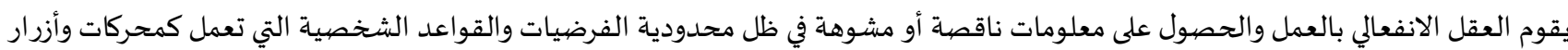

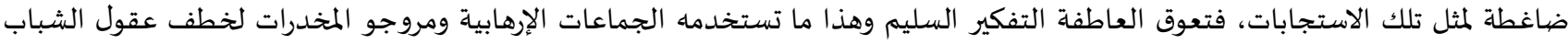
وجذبهم نحو المخاطر المختلفة.

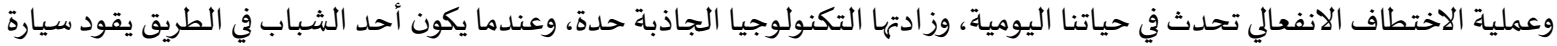

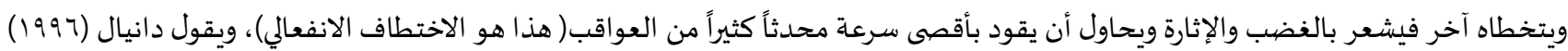

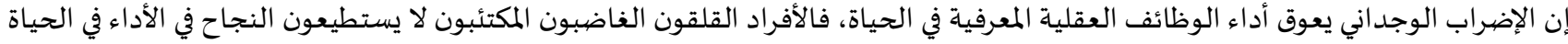

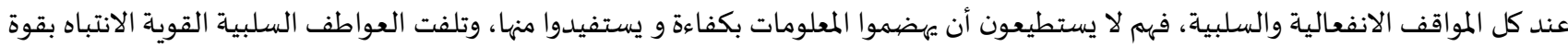

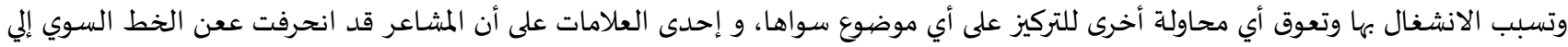

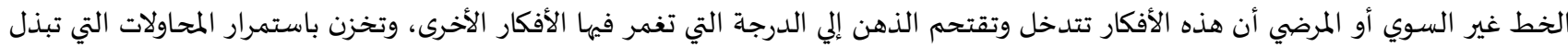

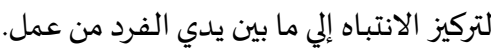



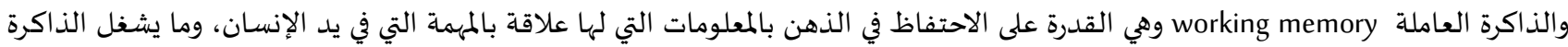



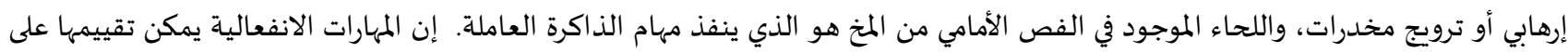

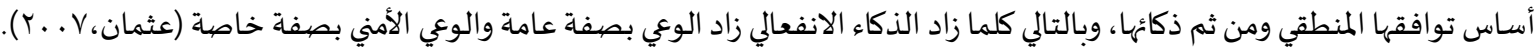

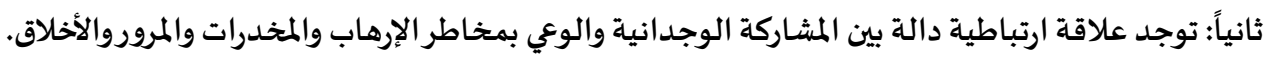

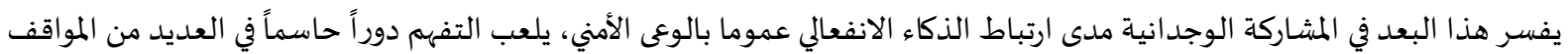

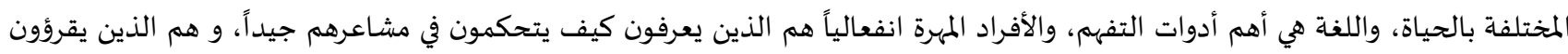

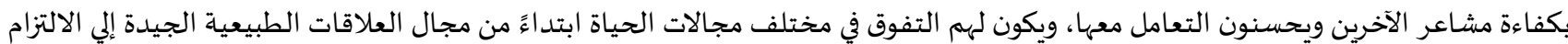

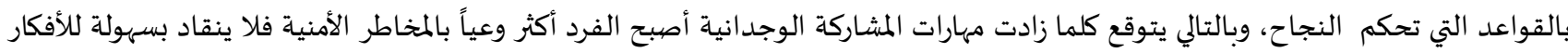

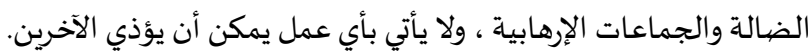

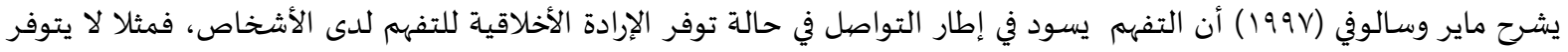

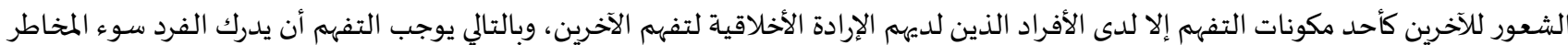

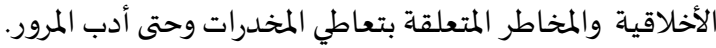
وترتبط المشاركة الوجدانية بمختلف مهاراتها بالوعي الأمني فمهارة تفهم المعاناة Suffering تحمي الفرد من إيذاء نفسها والآخرين، المشاركة

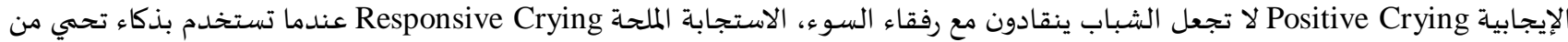

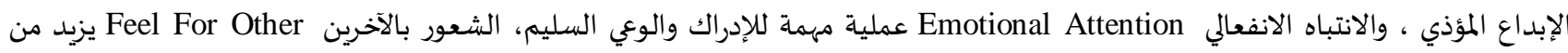

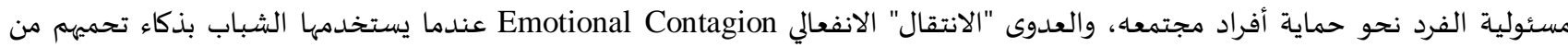

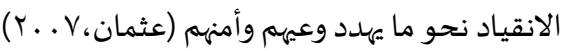

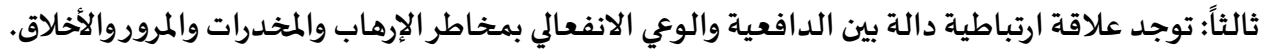

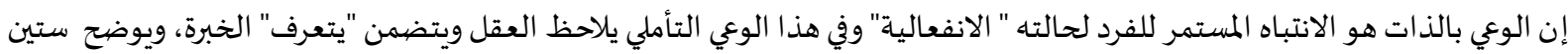

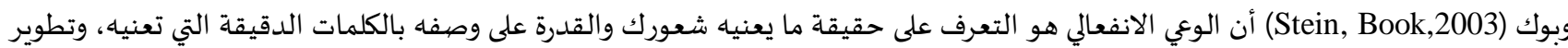
وتنظيم ذلك الشعور ، ويتضح أن الوعي بالانفعالات يتضمن فهم المشاعر وتفسيرها والقدرة على التعبير عنها وتميزها. 
إن من علامات نضجج الذكاء الانفعالي لدى الفرد هو انفتاحه على جميع الخبرات الانفعالية بطريقة سليمة، سواء كانت سارة أو غير سارة مما

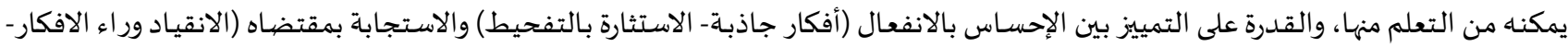

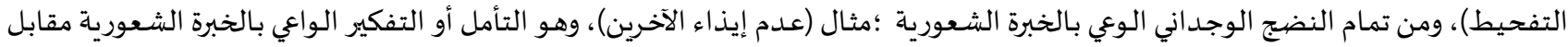

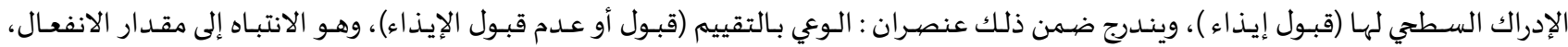

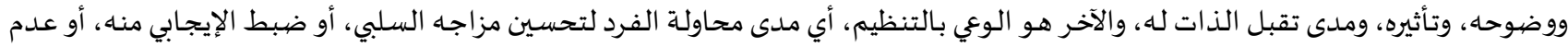



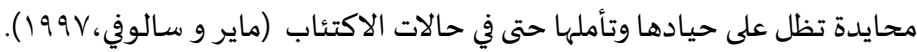

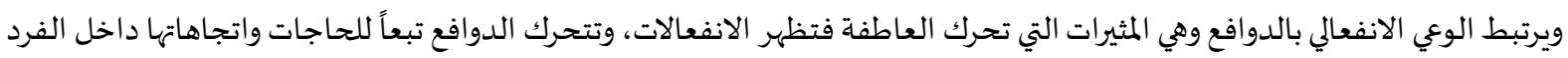

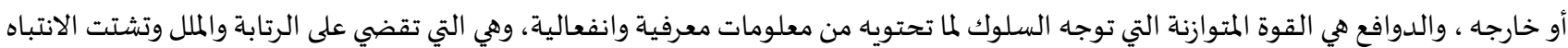



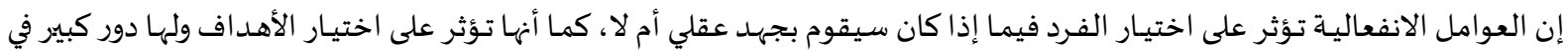

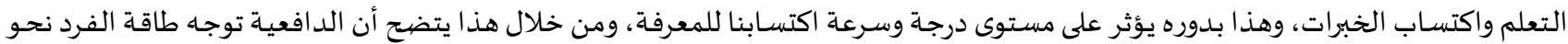

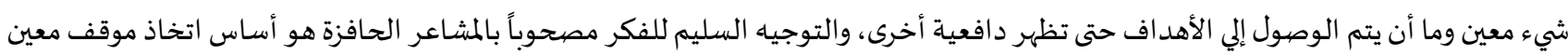

وحل مشكلة (Gardner, 1983).

تتمثل الدافعية في القدرة على تأجيل الاندفاع والتحكم في الانفعالات التي تؤدي بالفرد إلي الثقة بالنفس وإمكانية تحمل احباطات الحياة وعدم الهروب منها عبر مخاطر أمنية مختلفة (مخدرات- تفحيط وغيرها) وبالتالي كلما تم التحكم في الدافعية يختفي الشعور بالتمزق والانهزامية تحت أي نوع من الضغوط، ويتضمن التحكم في الاندفاعات وإمكانية استيعاب الفرد للموقف الاجتماعي وتكوين اقتناع ذاتي أن التحكم في الانفعالات مفيد بالنسبة لتكوينا الشخصي، وهكذا تضبط الدافعية عملية الوعى الأمني. رابعاً: توجد علاقة ارتباطية دالة بين تنظيم وإدارة الانفعالات والوعي بمخاطر الإرهاب والمخدلدرات والمرورووالأخلاق.

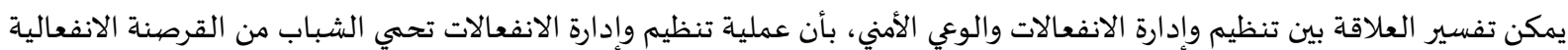
التي تؤدي إلى المخاطر الأمنية المختلفة. والقرصنة الانفعالية تحدث عندما يفقد المخ السيطرة الانفعالية في موقف مثير ويستمر عليه، وهي أكثر

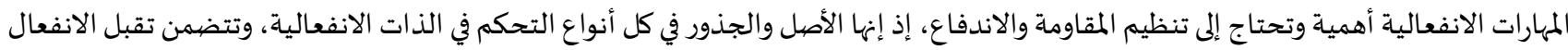
والتحكم باه وتنظيماه وإدارته بغض النظر عن كونه سـارا أو غير سار.

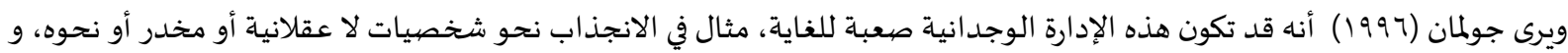

التي تحتوى على الكثير من الاحتياجات التي تمس الأعماق " كالشعور بالحب أو الإثارة أو الاحترام أو الخوف من الهجر والهابه والغيرة "

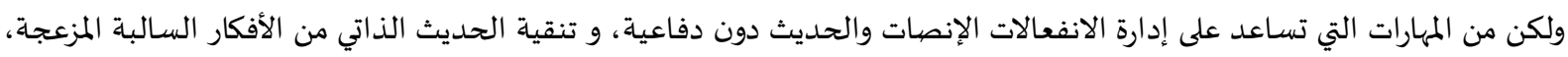

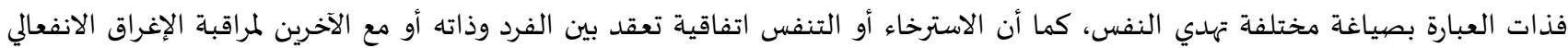
؛ واستخدام هذه الآليات الذكية يمنع حدوث القرصناعة الانفعالية.

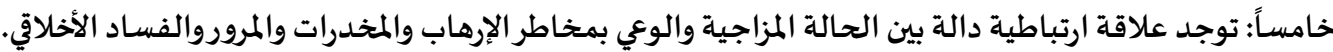
تتفق هذه النتيجة مع دراسة الحربي (1991) عن الخصائص المزاجية لمرتكبي حوادث المرور التي أسفرت عن وجود فروق دلالية إحصائية في

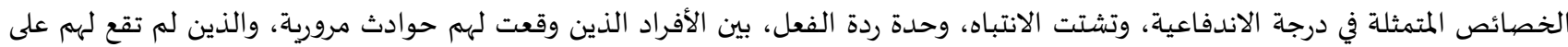
الإطلاق، لصالح الأفراد الذين وقعت لهم حوادث مرورية، وبينت عن عدم وجود فروق ذات دلالة إحصائية في الخصائص المزاجياة، بين الأفراد الذين

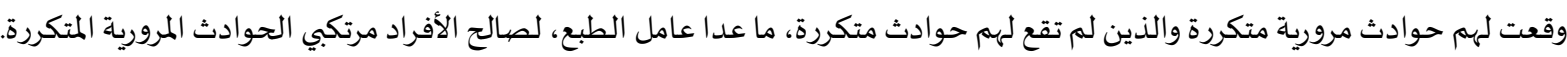
تستند الباحثة في تفسير الحالة المزاجية وأثرها على الوعي الأمني، على شرح بارون وباركر وجميس(Bar-on,Parker,James,2000) أنها بتأثير الانفعال المعتدل يزداد الخيال خصوبة، وينشط التفكير فتتدفق المعاني والأفكار في سرعة وسلاسة، كما تنشط الحئ الحركة ويزداد الميل إلى مواصلة العمل، بينما يشوه الانفعال العنيف التفكير المنظم والقدرة على حل المشكلات والتذكر والتعلم، وهذا ما يفسر العلاقة بين الحالة المزاجية والوعي

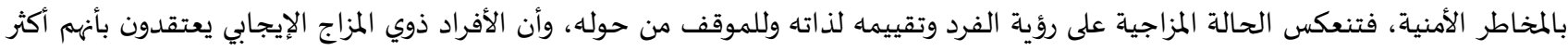

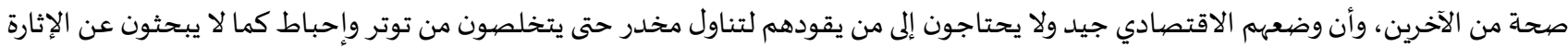

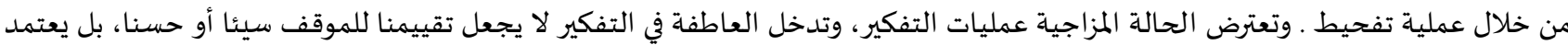
الأمر على كثير من المتغيرات في ذات الموقف تفحيط. 
إن استخدام مهارات الذكاء الانفعالي في التفتح على جميع الخبرات الوجدانية، السارة وغير السارة، يزيد مدارك الفرد وتعلمه، والاستجابة

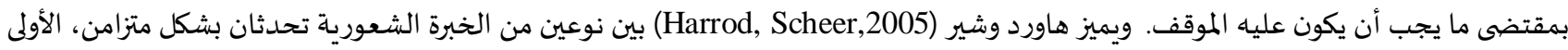

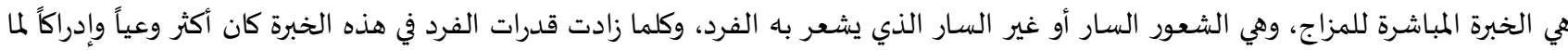

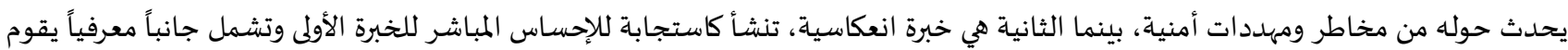
على مراقبة المزاج، أو ما أسمياه بالوعي المزاجي، ويحتاج الوعي المزاجي لمحاولات لتنظيماه، أو تغيير أثره في المستقبل وهذه خبرة مهمة تدخل في عملية وعي الفرد الأمني. ومن مكونات الحالة المزاجية الأمل، ومن منظور الذكاء الانفعالي امتلاك الأمل معناه أن الإنسان لن يستسلم للقلق القاهر أو الاتجاه

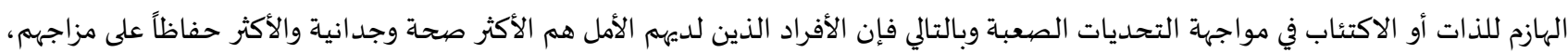

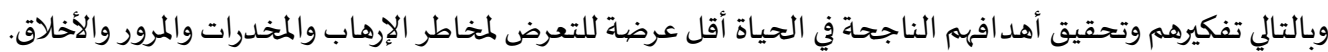

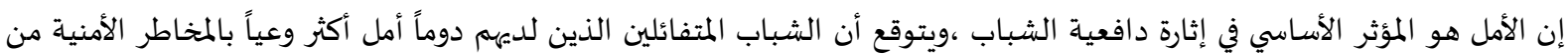

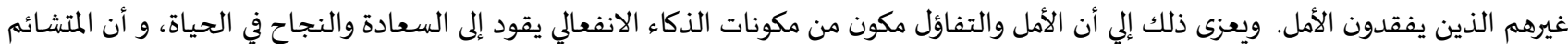
يعزي الإخفاق والرفض في حياته لأسباب ذاتية أو خارجية غير حقيقية تبعا لحالته الانفعالية السلبية التشاؤمية، وهذه التفسيرات يمكن أن تولد

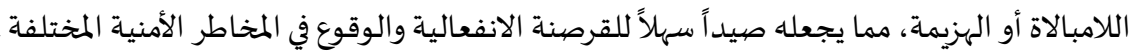

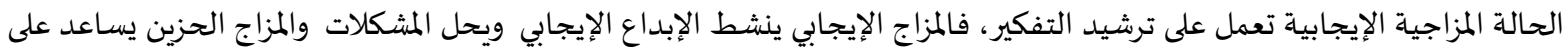
التفكير الاستدلالي وفحص البدائل المتاحة ، كما أن المشاعر الإيجابية تساعد الفرد على تصنيف وتئ وتنظيم المعلومات، وبالتالي يتعزز الوعي الأمني للفرد.

9

ا. تصميم برامج تدريبية لتنمية الذكاء الانفعالي للقيادات التعليمية، حتى يكوّنوا بيئة تعليم جيدة.

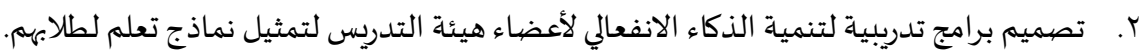
r. تصيميم مناهج تعليمية منفردة ومدمجة تبنى على تنمية الذكاء الانفعالي للطلاب. ع. تفعيل الأنشطة اللاصفية فمن خلالها يمارس ويطبق الطلاب قدراتهم الانفعالية بكفاءة.

$$
\text { 0. }
$$

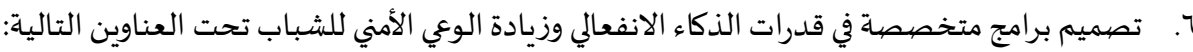
أ. برنامج تنمية اليسر الانفعالي لزيادة الوعي بالمخاطر الأمنية (الإرهاب- المخدرات- المرور- الفسادي الأخلاقي). ب. برنامج تنمية المشاركة الوجدانية لزيادة الوعي بالمخاطر الأمنية (الإرهاب- المخدرات- المرور - الفساد الأخلاقي).

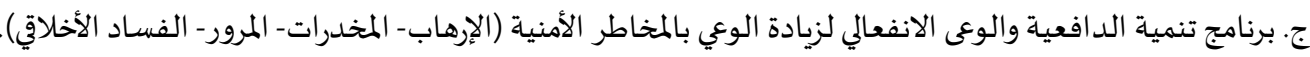

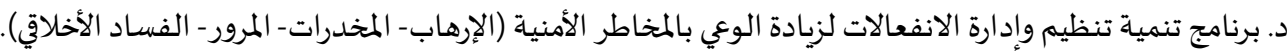

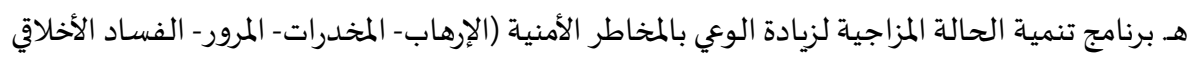

ا. البقهي، تركي بن عيد، (r ا ـr) دور الوعي الأمني في الوقاية من الجريمة الإرهابية. رسالة ماجستير، جامعة نايف العربية للعلوم الأمنية، كلية الدراسات العليا،

$$
\text { قسم العلوم الشرطية. }
$$

r. بوسنة، شريفة مصطفى،(0. . ب) تأثير العامل البشري على استفحال ظاهرة حوادث المرور : دراسة ميدانية عن عينة لضحايا حوادث المرور بالمؤسسة

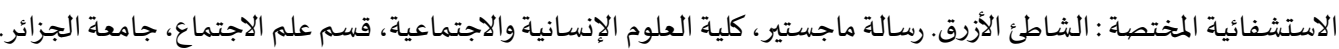



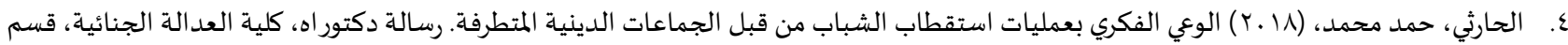
الدراسات الأمنية، تخصص مجدم، الدراسات الأمنية. جامعة نايف الوعيات العربية للعلوم الأمنية.

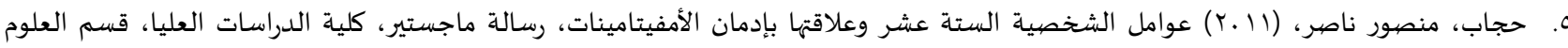
الاجتماعية، جامعة نايف العبية للعلوم الأمنية. 
7 ا. الحربي، محمد علي، (1991) بعض الخصائص المزاجية وأساليب المعاملة الوالدية كما يدركها الأبناء وعلاقتها بارتكاب الحوادث المرورية، رسالة دكتوراه ، أكاديمية أكسفورد للدراسات العليا بالتعاون مع جامعة أسيوط.



الاجتماعية، جامعة نايف العربية للعلوم الأمنية.

^. السحيمي، نايف بن مثيب، (1. ..ب) العوامل المؤدية إلى التغرير بالشباب للوقوع في الجرائم الإرهابية : دراسة تطبيقية على طلاب المرحلة الجامعية بمدينة

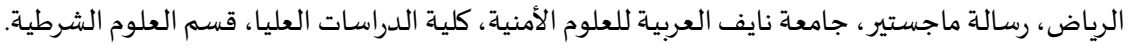

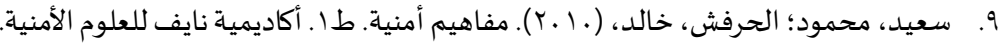

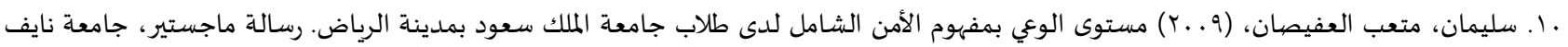

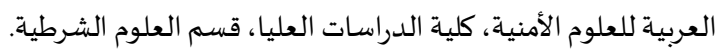

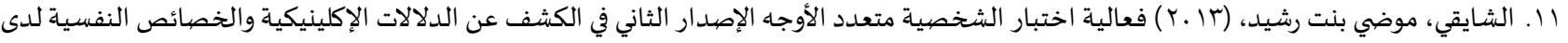

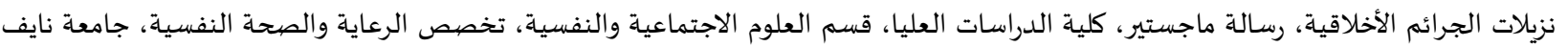
العربية للعلوم الأمنية.

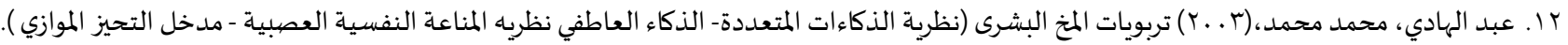

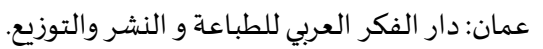

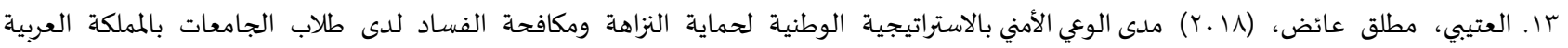

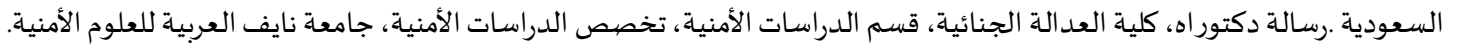

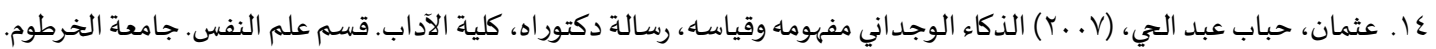

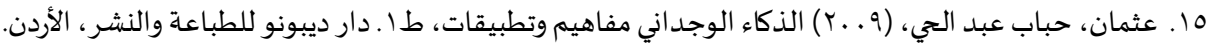

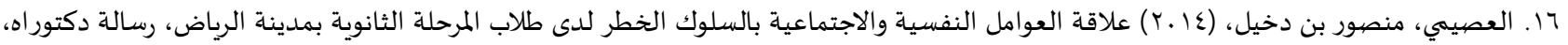

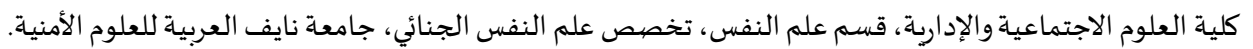

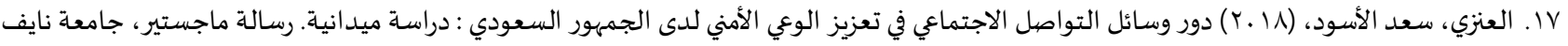
العربية للعلوم الأمنية.

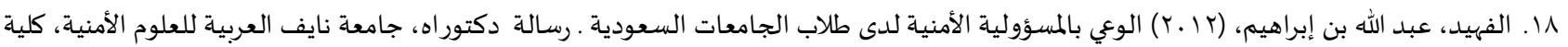
الدراسات العليا، قسم العلوم الاجتماعية.

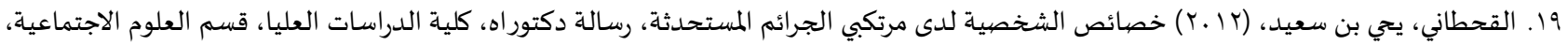
جامعة نايف العربية للعلوم الأمني.

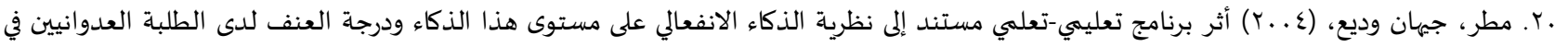
الصف الخامس والسادس، رسالة، الجامعة الأردنية.

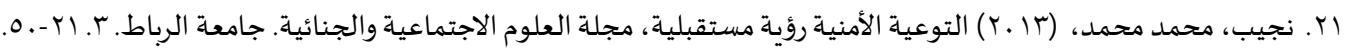

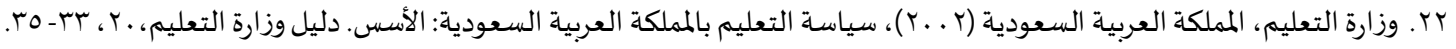

ثانياً: المراجع الأجنبية:

[1] Bar-on. R., \& Parker. I, James, D., Emotional Intelligence: Theory, Development, Assessment and Application at Home, School and the Work Place. San Francisco. U.S: Jossey. Bass Awilling Company, (2000)

[2] Cirrochi. Joseph., Forgas. P., \& Mayer. D., Emotional Intelligence in Every Day Life: A Scientific Inquiry. Philadelphia, USA: Psychology Press, (2001)

[3] David H. Cropley, James C. Kaufman \& Arthur J. Cropley, Malevolent Creativity: A Functional Model of Creativity in Terrorism and Crime, Creativity Research Journal 20(2)(2008), 105-115, http://dx.doi.org/10.1080/10400410802059424.

[4] Gardner H. New York: Basic Books; Frames of Mind, (1983)

[5] Gardner. Kathryn., Emotional Intelligence and Borderline Personality Disorder. Paper in University of Central Lancashire. At Psychology UK, (2007), Online Psychology Magazine First Published. http://www.e-intell.co.uk/ . 
[6] Golman. D., Emotional Intelligence Why can Matter MoreThan IQ. London: Bloomsbury Paperbacks, (1996)

[7] Harris. Daniel J.\& Reiter-Palmon. Roni, Fast and furious: The influence of implicit aggression, premeditation, and provoking situations on malevolent creativity, Psychology of Aesthetics, Creativity, and the Arts, 9(1)(2015), 54- 64, https://doi.org/10.1037/a0038499

[8] Harris. Daniel J.\& Reiter-Palmon. Roni; Kaufman, James C., The effect of emotional intelligence and task type on malevolent creativity. Psychology of Aesthetics, Creativity, and the Arts, 7(3)(2013), 237244, https://doi.org/10.1037/a0032139.

[9] Harrod. NR \& Scheer. SD, An exploration of adolescent emotional intelligence in relation to demographic characteristics, Adolescence, 40(2005):503-12. [PubMed].

[10] Henley. M \&Long. NJ, Teaching emotional intelligence to impulsive-aggressive youth, Reclaiming Child Youth, 7(1999),224-9.

[11] Kirsch. LG \&Becker. JV, Emotional deficits in psychopathy and sexual sadism: implications for violent and sadistic behavior. Clin Psychol Rev, 27(2007), 904-22. [PubMed].

[12] Mayer. J. D., \& Salovey, P., What is emotional intelligence? In P. Salovey and D. J. Shuyter (Eds). Emotional Development and emotional intelligence. New York: Implication for Educator, (1997)

[13] Mayer. J., Salovey. P., \& Caruso. D., Emotional Intelligence meets Traditional Standards for intelligence, Journal of Intelligence, 27(4)(2000), 267-298, https://doi.org/10.1016/s0160-2896(99)00016-1

[14] Megreya. AM., Criminal thinking styles and emotional intelligence in Egyptian offenders. Crim Behav Ment Health, 23(1)(2013),56-71, https://doi.org/10.1002/cbm.1854

[15] Melanie L. Beaussarta, Candace J. Andrewsa, James C. Kaufman, Creative liars: The relationship between creativity and integrity, Thinking Skills and Creativity.9(2014), 129-134, https://doi.org/10.1016/j.tsc.2012.10.003

[16] Petrides. KV, Frederickson. N \& Furnham. A., The role of trait emotional intelligence in academic performance and deviant behavior at school. Pers Individ Dif,36(2)(2004), 277-93, https://doi.org/10.1016/s0191-8869(03)00084-9

[17] Pizarro. DA \& Salovey P., On being and becoming a good person: The role of emotional intelligence in moral development and behavior. In: Aronson J, editor. Improving Academic Achievement: Impact of Psychological Factors on Education. San Diego: Academic Press. 247-66.

[18] Schulze. R., \& Roberts. R., Emotional Intelligence. International Book. Cambridge: Hogerfe and Huber, (2005)

[19] Sharma. Neelu , Om Prakash, Sengar. K. S. , Chaudhury. Suprakash , Singh. Amool R., The relation between emotional intelligence and criminal behavior: A study among convicted criminals, Ind Psychiatry J, 24(1)(2015),pp.54, https://doi.org/10.4103/0972-6748.160934

[20] Stein. S., \& Book, H. (2003). The EQ Edge: Emotional Intelligence and your success. Toronto. Canada: Multi- Health System.

[21] Strüber. D, Lück. M \&Roth. G, Sex, aggression and impulse control: An integrative account. Neurocase 14(1)(2008),93-121, https://doi.org/10.1080/13554790801992743

[22] Van Den Berg. P \&Van Aarle. C.,A model for motivational synergy in creative environment. Paper presented at 26th International Congress of Applied Psychology, Athens, Greece. Hellenic Psychological Society, 1. 54(2006). 


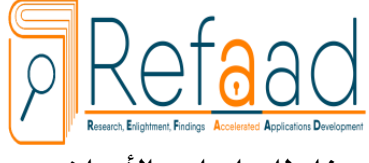

رفاد للدراسات والأبحاث

www.refaad.com
المجلة الدولية للدراسات التربوية والنفسية

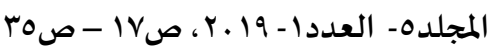

e-ISSN 2520-4149, p-ISSN 2520-4130

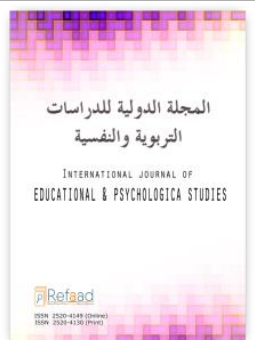

\title{
Identify the Relationship Between Emotional Intelligence and Awareness of the Security Risks of the Students of Tabuk University
}

\section{Habbab Abdul Hai Mohammed Othman}

Assistant Professor of Psychology, Faculty of Education and Arts, Tabuk University, Saudi Arabia h-othman@ut.edu.sa

\begin{abstract}
The objective of the study was to identify the relationship between emotional intelligence and awareness of the security risks of the students of Tabuk University. Use the descriptive method, and to collect the information. Prepare the emotional intelligence scale and the security risk awareness questionnaire, and apply it to a random sample of students from Tabuk University. , And the following results: There is a positive relationship between the emotional intelligence and awareness of security risks for students of the University of Tabuk, there is a positive relationship of statistical significance between emotional intelligence and awareness of the dangers of terrorism, and drugs, and traffic, and moral corruption.

There is also a relationship between the dimensions of emotional intelligence (Facilitating emotions for thinking, Empathy, Motivation and emotional awareness, Managing Emotion, The mood), and the dimensions of security awareness (terrorism, drugs, traffic, moral corruption).
\end{abstract}

Keywords: emotional intelligence, security awareness, terrorism, drugs, traffic, moral corruption.

\section{References:}

- Ạlqrận Ạlkrym Wạlsnh Ạlnbwyh.

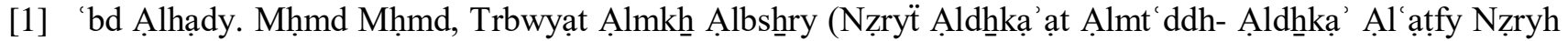
A.lmnậh Ạlnfsyh Ạl'ṣbyh-Mdkḥl Ạltḥyz Ạlmwạzy). 'mạn: Dạr Ạlfkr Ạl'rby Llṭ̣ậh W Ạlnsḥr Wạltwzy', (2003)

[2] 'tḥmạn. Ḥbạb 'bd Ạlḥ̣y, Ạldh̄kạ’ Ạlwjdạny Mfhwmh Wqyạsh, Rsạlẗ Dktwrạh, Klyë Ạlậdạb. Qsm 'lm Ạlnfs. Jạm ‘̈ Ạlkhrțwm, (2007)

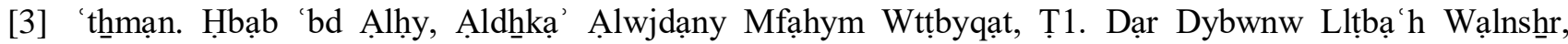
Ạlạ̉rdn, (2009)

[4] All'nzy. S'd Ạlạ̉swd, Dwr Wsạyl Ạltwạșl Ạlạjtmạ y Fy T'zyz Ạlw'y Ạlạ̉mny Lda Ạljmhwr Ạls wody: Drạsh Mydạnyh, Rsạlẗ Mạjstyr, Jạm ‘̈ Nạyf Ạl'rbyh Ll'lwm Ạlạ̉mnyh, (2018)

[5] Ạl'ṣymy. Mnșwr Bn Dkḥyl, 'lạqü Ạl'wạml Ạlnfsyh Wạlạjtmạ yh Bạlslwk Ạlkḥțr Ldy Ṭlạb Ạlmrḥlh

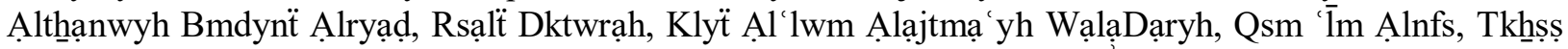
'lm Ạlnfs Ạljnạyy, Jạm‘đ̈ Nạyf Ạl'rbyh Ll'lwm Ạlạ̉mnyh, (2014)

[6] Ạl'tyby. Mṭlq ‘ạyḍ̣, Mda Ạlw’y Ạlạ̉mny Bạlạstrạtyjyh Ạlwṭnyh Lhmạyh Ạlnzạhh Wmkạfḥh Ạlfsạd Lda Ṭlạb Ạljạm ạt Bạlmmlkh Al'rbyh Ạls'wdyh, Rsạlẗ Dktwrạh, Klÿ̈ Ạl'dạlh Ạljnạyyh, Qsm Ạldrạsạt Ạlạ̉mnyh, Tkhṣṣ Ạldrạsạt Ạlạ̉mnyh, Jạm ‘̈ Nạyf Ạl'rbyh Ll'lwm Ạlạ̉mnyh, (2018) 
[7] Ạlbqmy. Trky Bn 'yd, Dwr Ạlw'y Ạlạ̉mny Fy Ạlwqạyh Mn Ạljrymh ẠlạRhạbyh, Rsạlẗ Mạjstyr, Jạm‘̋̈ Nạyf Ạl'rbyh Ll'lwm Ạlạ̉mnyh, Klyẗ Ạldrạsạt Ạl'lyạ, Qsm Ạl' lwm Ạlshrț̣h, (2012)

[8] Ạlfhyd. 'bd Ạllh Bn ABrạhym, Ạlw’y Bạlmsw̉wlyh Ạlạ̉mnyh Lda Ṭlạb Ạljạm ‘ạt Ạls'wdyh, Rsạlẗ Dktwrạh, Jạm ‘̈ Nạyf Ạl'rbyh Ll'lwm Ạlạ̉mnyh, Klÿ̈ Ạldrạsạt Ạl'lyạ, Qsm Ạl' lwm Ạlạjtmạ yh, (2012)

[9] Alhạrthyy. Hmd Mḥmd, Alw'y Ạlfkry B'mlyạt Ạstqțạb Ạlsḥbạb Mn Qbl Aljmạ ạt Ạldynyh Ạlmtțrfh, Rsạlẗ Dktwrạh, Klyẗ Ạl dạlh Ạljnậ̉yh, Qsm Ạldrạsạt Ạlạ̉mnyh, Tkḥṣ̣ Ạldrạsạt Ạlạ̉mnyh, Jạm đ̈ Nạyf Ạl'rbyh Ll'lwm Ạlạ̉mnyh, (2018)

[10] Ạlḥrby. Mḥmd 'ly, B'ḍ Alkḥsạyṣ Ạlmzạjyh Wạ̉sạlyb Alm'ạmlh Ạlwạldyh Kmạ Ydrkhạ Alạ̉bnạ' W'lạqthạ Bạrtkạb Ạlḥwạdth Ạlmrwryh, Rsạlt Dktwrạh , Ạ̉kạdymÿ̈ Ạ̉ksfwrd Lldrạsạt Ạl'lyạ Bạlt ận M'Jạm ‘̈ Ạ̉sywț, (1998)

[11] Ạlkḥlf. 'mr Bn Nạṣr, Mstwa Ạltwạfq Ạlạnf'ạly Wạlạjtmạ y Ldy Ạlmt'ạtyn Wgḥyr Ạlmt'ạtyn. Rsạlẗ Mạjstyr, Klyẗ Ạldrạsạt Ạl'lyạ, Qsm Ạl'lwm Ạlạjtmạ yh, Jạm ‘̈ Nạyf Ạl'rbyh Ll'lwm Ạlạ̉mnyh, (2007)


Ạldrạsạt Ạl'lyạ, Qsm Ạl'lwm Ạlạjtmạ yho Jạm ‘̈ Nạyf Ạl'rbyh Ll'lwm Ạlạ̉mny, (2012)

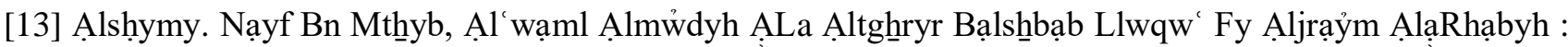

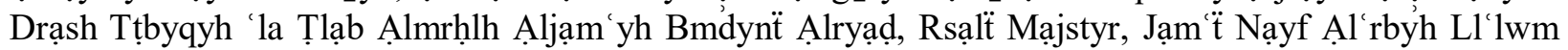
Ạlạ̉mnyh, Klÿ̈ Ạldrạsạt Ạl' lyạ, Qsm Ạl' lwm Ạlsḥrțhh, (2008)

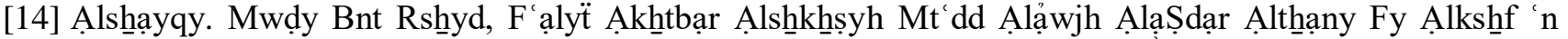
Ạldlạlạt ẠlạKlynykyh Wạlkḥsạyṣ Ạlnfsyh Lda Nzylạt Ạljrậ̉m Alạ̉khlạqyh, Rsạlẗ Mạjstyr, Klyẗ Ạldrạsạt

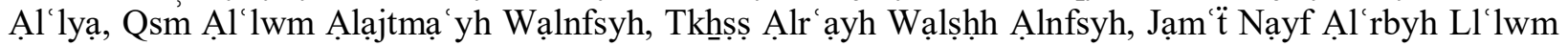
Ạlạ̉mnyh, (2013)

[15] Bar-on. R., \& Parker. I, James, D., Emotional Intelligence: Theory, Development, Assessment and Application at Home, School and the Work Place. San Francisco. U.S: Jossey. Bass Awilling Company, (2000)

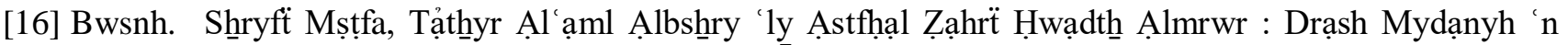

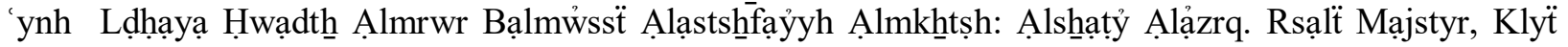
Ạl'lwm ẠlạiNsạnyh Wạlạjtmạ yh, Qsm 'Im Ạlạjtmạ', Jạm ‘̆ Ạljzậr, (2005)

[17] Cirrochi. Joseph., Forgas. P., \& Mayer. D., Emotional Intelligence in Every Day Life: A Scientific Inquiry. Philadelphia, USA: Psychology Press, (2001)

[18] David H. Cropley, James C. Kaufman \& Arthur J. Cropley, Malevolent Creativity: A Functional Model of Creativity in Terrorism and Crime, Creativity Research Journal 20(2)(2008),105-115, http://dx.doi.org/10.1080/10400410802059424.

[19] Gardner H. New York: Basic Books; Frames of Mind, 1983

[20] Gardner. Kathryn., Emotional Intelligence and Borderline Personality Disorder. Paper in University of Central Lancashire. At Psychology UK, (2007), Online Psychology Magazine First Published. http://www.e-intell.co.uk/ .

[21] Golman. D., Emotional Intelligence Why can Matter MoreThan IQ. London: Bloomsbury Paperbacks, (1996)

[22] Harris. Daniel J.\& Reiter-Palmon. Roni, Fast and furious: The influence of implicit aggression, premeditation, and provoking situations on malevolent creativity, Psychology of Aesthetics, Creativity, and the Arts, 9(1)(2015), 54- 64, https://doi.org/10.1037/a0038499 
[23] Harris. Daniel J.\& Reiter-Palmon. Roni; Kaufman, James C., The effect of emotional intelligence and task type on malevolent creativity. Psychology of Aesthetics, Creativity, and the Arts, 7(3)(2013), 237244, https://doi.org/10.1037/a0032139.

[24] Harrod. NR \& Scheer. SD, An exploration of adolescent emotional intelligence in relation to demographic characteristics, Adolescence, 40(2005):503-12. [PubMed].

[25] Henley. M \&Long. NJ, Teaching emotional intelligence to impulsive-aggressive youth, Reclaiming Child Youth, 7(1999),224-9.

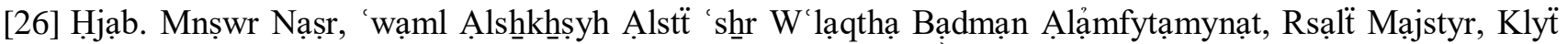
Ạldrạsạt Ạl'lyạ, Qsm Ạl'lwm Ạlạjtmạ yh, Jạm ‘̈̉ Nạyf Ạl'rbyh Ll'lwm Ạlạ̉mnyh, (2011)

[27] Jạbr. 'bd Ạlhmmyd Jạbr, Nhw T'lym Ạ̉fụl Ạnjạz Ạ̉kạdymy Wt'lm Ạjtmạ y Wdh̄kạ’ Wjdạny. Ạlqạhrh: Dạr Alfkr Al'rby, (2004)

[28] Kirsch. LG \&Becker. JV, Emotional deficits in psychopathy and sexual sadism: implications for violent and sadistic behavior. Clin Psychol Rev, 27(2007), 904-22. [PubMed].

[29] Mayer. J. D., \& Salovey, P., What is emotional intelligence? In P. Salovey and D. J. Shuyter (Eds). Emotional Development and emotional intelligence. New York: Implication for Educator, (1997)

[30] Mayer. J., Salovey. P., \& Caruso. D., Emotional Intelligence meets Traditional Standards for intelligence, Journal of Intelligence, 27(4)(2000), 267-298, https://doi.org/10.1016/s0160-2896(99)00016-1

[31] Megreya. AM., Criminal thinking styles and emotional intelligence in Egyptian offenders. Crim Behav Ment Health, 23(1)(2013),56-71, https://doi.org/10.1002/cbm.1854

[32] Melanie L. Beaussarta, Candace J. Andrewsa, James C. Kaufman, Creative liars: The relationship between creativity and integrity, Thinking Skills and Creativity.9(2014), 129-134, https://doi.org/10.1016/j.tsc.2012.10.003

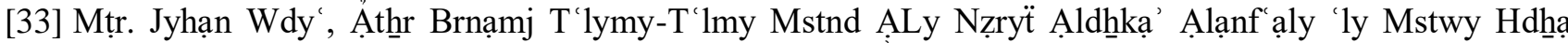

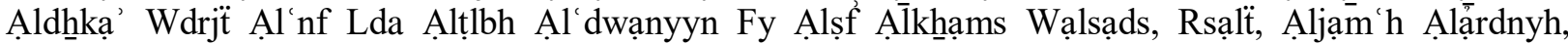
(2004)

[34] Njyb. Mḥmd Mḥmd, Ạltw'yh Ạlạ̉mnyh Rw̉yh Mstqblyh, Mjlï Ạl'lwm Ạlạjtmạ yh Wạljnạyyh, Jạm‘̈̈ Alrbạt. 3(2013), 21-50.

[35] Petrides. KV, Frederickson. N \& Furnham. A., The role of trait emotional intelligence in academic performance and deviant behavior at school. Pers Individ Dif,36(2)(2004), 277-93, https://doi.org/10.1016/s0191-8869(03)00084-9

[36] Pizarro. DA \& Salovey P., On being and becoming a good person: The role of emotional intelligence in moral development and behavior. In: Aronson J, editor. Improving Academic Achievement: Impact of Psychological Factors on Education. San Diego: Academic Press. 247-66.

[37] S yd.Mḥmwd \&Ạlḥrfsh. Khạld, Mfạhym Ạ̉mnyh, Ṭ1, Ạ̉kạdymyë Nạyf Ll'lwm Ạlạ̉mnyh, (2010)

[38] Schulze. R., \& Roberts. R., Emotional Intelligence. International Book. Cambridge: Hogerfe and Huber, (2005)

[39] Sharma. Neelu , Om Prakash, Sengar. K. S. , Chaudhury. Suprakash , Singh. Amool R., The relation between emotional intelligence and criminal behavior: A study among convicted criminals, Ind Psychiatry J, 24(1)(2015),pp.54, https://doi.org/10.4103/0972-6748.160934 


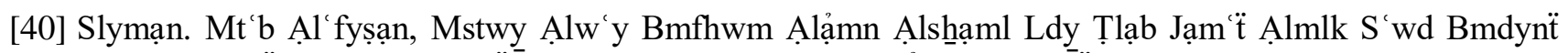

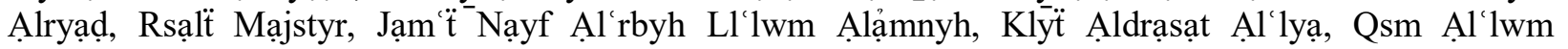
Ạlshrțh, (2009)

[41] Stein. S., \& Book, H. (2003). The EQ Edge: Emotional Intelligence and your success. Toronto. Canada: Multi- Health System.

[42] Strüber. D, Lück. M \&Roth. G, Sex, aggression and impulse control: An integrative account. Neurocase 14(1)(2008),93-121, https://doi.org/10.1080/13554790801992743

[43] Van Den Berg. P \&Van Aarle. C.,A model for motivational synergy in creative environment. Paper presented at 26th International Congress of Applied Psychology, Athens, Greece. Hellenic Psychological Society, 1. 54(2006).

[44] Wzạrä Ạlt' lym, Ạlmmlkh Ạl'rbyh Ạls'wdyh, Syạsẗ Ạlt'lym Bạlmmlkh Ạl'rbyh Ạls 'wdyh: Ạlạ̉ss. Dlyl Wzạrẗ Ạlt'lym,20(2002), 33- 35. 